\title{
TRANSACTIONS THAT DID NOT HAPPEN AND THEIR INFLUENCE ON PRICES
}

\author{
ALAN KIRMAN \\ GREQAM, EHESS, IUF \\ 2 Rue de la Vieille Charité \\ 13002 Marseille, France \\ WOLFGANG HÄRDLE, RAINER SCHULZ, AXEL WERWATZ* \\ CASE - Center for Applied Statistics and Economics \\ Institute for Statistics and Econometrics, SFB 373 \\ School of Business and Economics \\ Humboldt-Universität zu Berlin
}

June 2002

\begin{abstract}
This paper studies data from the wholesale fruit and vegetables market in Marseille. We have details of counteroffers to the prices that were proposed by the seller even when no transaction took place. With a simple theoretical model we analyse the evolution of prices during the day and in particular the relation between the final price struck and the proposals of the two parties. Periods with no buyer refusals, of offers or bargaining with no transaction will
\end{abstract}

*A first version of this paper was presented at the First World Congress of the Game Theory Society in Bilbao. Helpful comments from the participants there and from Alessandra Casella, Veronika Grimm, Sylvie Thoron and Jorgen Weibull are gratefully acknowledged. Financial support from the Deutsche Forschungsgemeinschaft, SFB 373 is gratefully acknowledged. 
lead to a revision of the seller's first price. More importantly the sharing of the surplus moves in the buyer's favour during the day. These presumptions are then shown to be confirmed by our data set.

JEL Codes: C78, D44, Q13

Keywords: Bargaining, Markets

\section{Introduction}

The bargaining literature presents several problems when one confronts it with empirical facts. In many markets, unlike the situation in the Rubinstein (1982) framework haggling does, in fact, take place. It is almost never the case that we have details of the intermediate offers and counteroffers that make up such haggling and this is particularly true of those cases in which bargaining took place but no bargain was struck. Data on final transactions does not reveal the process by which the final bargain was arrived at. This would be of no importance if the offers and counteroffers that are made during the bargaining process had no influence on the final outcome. However, if we regard them as revealing information then this is unlikely to be the case.

In this paper we present evidence from the wholesale fruit and vegetable market in Marseille and we analyse the data for four products. This data contains details of the prices asked and the counteroffers made even when no transaction took place. This situation is difficult to fit into the existing literature. What happens in reality is that both buyer and seller get information about "the state of the market" as 
the day goes on. Each price proposed conveys information to the buyer and each counteroffer, or refusal provides information for the seller.

In a market with perishable goods or in one where buyers can be separated according to how long they remain in the market one might expect to see declining prices over the day. Although in a world where waiting is not costly the prices at the end of the day should be the same as at the beginning if the appropriate strategies were adopted there are various explanations for the fact that, in reality, descending prices are frequently observed. The literature on the "declining price phenomenon" in auctions, Ashenfelter (1989); McAfee and Vincent (1993); PezanisChristou (1997) bears witness to this. However, curiously in Härdle and Kirman (1995), we found that this feature was essentially absent from the Marseille fish market.

To get a clearer picture of the evolution of prices in this market, one could think of relating the analysis to the bargaining under two-sided uncertainty literature. In that case, both buyer and seller have information which is unknown to the other, and it is typically assumed that the information in question is the "value" of the object over which bargaining is taking place. In our case the information that is being implicitly conveyed is the aggregate quantity available and hence which prices may obtain. Thus, a refusal of a price by a buyer may reflect his having found a cheaper price elsewhere or that he has little fear of not finding what he wants elsewhere. This information should be useful to the seller who may then modify 
the price he has set. Similarly, if several buyers, in succession, accept the price asked immediately then the seller might reasonably infer that this product is in short supply and then modify his price accordingly. In other words, the behaviour of the buyer is a signal about his reservation price which, in turn, reflects his ideas about the distribution of prices available. The problem is that the situation we have described does not correspond to the standard literature since several different partners are involved successively. Thus the offers and counteroffers in one matching influence those made in a subsequent matching but the new partner does not have the same information as if he were there from the outset.

If all agents of each type, buyer or seller were identical, the fact that the market unfolds in this fashion would have no significance. However, the problem would be of a different nature since each seller would be aware of the state of the market from the outset. As it is, sellers obtain their stocks from different sources, they have certain clients who are loyal and do not go elsewhere, and the clients have different demands. Thus, although the price charged to each particular buyer is specific to the seller involved, that price is influenced by the general state of the market. What price I, as a buyer, can obtain today will depend on what the seller I visit has had to pay and his view of the quantity available on the market today. The maximum price that I am willing to accept, my reservation price, will depend on the offers that I have obtained previously and my view of the quantity available. Each time there is a meeting information is conveyed and the price asked in the next period 
may be influenced by that information. Since our data is for one seller we cannot track the reactions of buyers as they move from one seller to another. However, we can observe the reactions of our seller to each meeting. The purpose of this paper is to examine those reactions.

\section{Our data}

We have data for 15 trading days in March of the year 1983. In total, we have 3960 observations for 4 kinds of fruit and vegetables. These are leek, domestic tomatoes, imported tomatoes and oranges. The oranges and the imported tomatoes are from Spain, whereas the leek and the domestic tomatoes are from France. Every trading day is divided into time grids. From 7 to 9 o'clock, the length of a grid is 2 minutes 30 seconds. Thus, there are 48 time intervals with equal length. From 9 to 12 o'clock, the length of the grid is 10 minutes. Thus, there are 18 intervals of equal length.

Figure 1 depicts the way in which a meeting on the wholesale fruit and vegetable market in Marseille might unfold. The seller makes an initial price offer $p_{1}^{*}$ which is either accepted or rejected. If the buyer accepts a Transaction occurs with No Bargaining (TNB) at the offered price. Thus, the transaction price $p$ is equal to $p_{1}^{*}$. If the buyer rejects he may either make a counteroffer $c$ or walk away. In the latter case, the meeting ends without a deal being struck and we Only observe the seller's 
Offer price $(\mathbf{O O})$. If he makes a counteroffer then both parties either agree on a transaction price somewhere in the closed interval defined by $c$ and $p_{1}^{*}$ or stop the negotiation. In the wholesale fruit and vegetable market in Marseille this final round of bargaining usually takes the form of the seller making a second and final price offer $p_{2}^{*}$, given $c$ and $p_{1}^{*}$. If the buyer accepts then we observe three prices - that are $p_{1}^{*}, c$, and $p_{2}^{*}$-and refer to this outcome as a Transaction With Bargaining (TWB). In that case, the transaction price $p$ is equal to $p_{2}^{*}$. In the other case we observe the seller's initial Offer and the buyer's Counteroffer (OC) but no transaction occurs.

[Figure 1 about here.]

[Table 1 about here.]

Table 1 shows the relative frequency of these different categories of encounters for the different sorts of vegetables, cumulated over all days. Whereas the frequencies of "offer only" and "offer and counteroffer" for the two types of tomatoes and oranges are quite similar, the behavior on the leek market is different. For the former vegetables, in less than $2.5 \%$ of contacts no transaction occurs. For the latter, about $17.5 \%$ of all contacts end without a transaction. The total frequency of contacts with counteroffers are $35.05 \%$ for leek, $28.69 \%$ for domestic tomatoes, $35.26 \%$ for imported tomatoes and $40.51 \%$ for oranges. However, we have also examined the frequencies of the last four categories that are equivalent to a contact. Table 2 shows the distribution of the categories given that a contact happened. The first 
two columns confirm the observation that it was more difficult to strike a deal for leek than for the other products.

[Table 2 about here.]

As we have already mentioned, this observation grid is not equally spaced. Whereas we have 48 observations per product and day before 9 o'clock, we have only 18 observations from 9 to 12 o'clock. To take account of this, we separated the data and Tables 3, 4, 5 and 6 will present the distributions of the different categories for the two different observation periods.

[Table 3 about here.]

[Table 4 about here.]

[Table 5 about here.]

[Table 6 about here.]

An important question is as to how the negotiations evolve during the course of the day? Figure 2 shows that the number of negotiations for leek diminished during the trading day. This result reflects the first entries in Tables 3 and 5 . The fact of a diminishing number of negotiations is much more pronounced for domestic tomatoes, see Figure 3. We observe no negotiation after 9.50 o'clock. This illustrates the result from Table 5; in $98.5 \%$ of the time after 9 o'clock no contact happens. In contrast 
to the results for the domestic products, the number of negotiations increases for imported tomatoes and oranges, see Figure 4 and [5. Once again, this is in accordance with the entries in the above mentioned Tables. The frequencies of contacts show that the relative negotiations volume is increasing during the course of the day. Thus, the behavior for domestic products and imported products is different. With respect to the relative frequency of meetings with counteroffer, the products are quite similar, see Figures 6 to 9 ,

[Figure 2 about here.]

[Figure 3 about here.]

[Figure 4 about here.]

[Figure 5 about here.]

[Figure 6 about here.]

[Figure 7 about here.]

[Figure 8 about here.]

[Figure 9 about here.]

In this paper we use our data to shed light on the following questions: 1. How did the prices offered by the seller evolve during the day? 2. How did the sellers' prices 
react to a successful transaction or to the failure to transact? 3. How did buyers' counteroffers evolve over the day? 4. What was the influence of the difference between the seller's price and that of the buyer on the probability of a transaction? 5. How did the transaction price relate to the seller's and buyer's price and did this vary over the day?

\section{Related theoretical approaches}

As has been mentioned, at first sight the problem posed here might be thought of as corresponding to a bargaining situation with two-sided uncertainty. The price that a seller is willing to accept is unknown to the buyer and the price that a buyer is willing to pay is unknown to the seller at each point in time. This setting seems to be related to that in which each player has a private reservation value as described by Myerson and Satterthwaite (1983). However, for their results they require that the reservation values be drawn from distributions, which are known to each of the partners, even though the particular values are not known. In our case the values are under constant revision. Each meeting corresponds to the situation involved in Myerson and Satterthwaite] s analysis except for the fact that the distribution of each player's reservation value has been modified by his experience. Thus, at any point in time there is no reason to believe that the distributions of the two bargainers will coincide. 
The question then becomes one of what happens when both partners have formed an idea of the state of the market. In this case one would expect to find a convergence to a conventional bargaining problem. A second problem arises in our particular case. Learning is accompanied by transactions; the process is one of nontatonnement. Thus the reservation price of the parties will be conditioned not only by their knowledge of the market situation but also by their sales or purchases up to that point.

Given these difficulties we tried, as a first approach, to examine a certain number of plausible hypotheses and to establish a certain number of stylised facts, which would be consistent with the theory for simpler situations.

The central theme of this paper is the influence of bargaining on the probability of transactions and on the behaviour of buyers and sellers. A model developed by Grossman and Perry (1986) is related our analysis. They developed a model in which a buyer bargains with a seller and where information about the reservation prices is incomplete. In their case the distribution of the buyer's reservation price is known but the realisation is not. The seller's reservation price is assumed to be public knowledge. The negotiation involves one indivisible unit of a good. The game is structured as follows:

- At $t$ the seller makes an initial offer

- At $t+1$ the buyer accepts or makes a counteroffer 
- At $t+2$ the seller accepts the counteroffer or makes a new offer

- This process continues until an offer is accepted.

At each point in time the seller has a prior distribution on the buyer's reservation price, $F(x)$ and in the Grossman Perry model this distribution is common knowledge. In their model an action for a player is an acceptance of the previous offer or a new counteroffer.

In their model there is a discount factor $\delta$ such that if the expected value for the player of playing the game today is $V(a, b)$ then the value tomorrow if there no change in the support of the distribution is $\delta V(a, b)$.

In our case the value of waiting is the value of playing with the next buyer or seller.

The basis result shown by Grossman and Perry is that one will observe a series of offers and counteroffers terminating in an offer that is accepted. The essential feature of the model which tends to negotiations actually being observed is the asymmetric information. Negotiations reveals the information about the buyer's reservation price.

In our case the result of Grossman and Perry does not apply directly since the seller's reservation price is not zero but is what he considers to be the value of playing with someone else. Their model does, however provide us with insight as to how the process develops between two agents and suggests that one should see offers 
which are taken, counteroffers which are accepted and new offers which are accepted. The distribution $F(x)$ is revised at time $t$ and we must then ask the question as to how the observations up to a certain point affect the revision. The difficulty about models such as that of Grossman and Perry is that they require full-blown game theoretic reasoning. In what follows we will specify the behaviour of our seller with a more limited reasoning. After making some observations about how the buyer's reservation prices will shift over time we will present a model which represents the seller's choice of his initial price and then a revision process and finally we will consider what the predicted sign of the effect of various types of observation should be on the parameter governing the revision process.

\subsection{Buyer's behaviour}

An important question here is as to how buyers revise their reservation prices. They are searching in the market and given the distribution of prices that they observe they will modify their reservation prices. Can we reduce our situation to that analysed in standard search models? There the situation is clear. There is a distribution of sellers' prices amongst which buyers search and, in the standard version, the rule is simple. Consider that price which is such that the gain from an additional search is just equal to the cost of making that search, call this the reservation price. Then

search until one finds a price which is less than or equal to this value. Formally if the 
cumulative density of prices is given by $F(p)$ and the cost is $c$, then the reservation price is given by $R$ such that:

$$
\int_{0}^{R}(R-p) d F(p)=\int_{0}^{R} F(p) d p=c
$$

The first problem is that $F$ is assumed to be known and to be fixed during the search. This is important since as Gastwirth (1976) pointed out the mis-specification of $F$ may lead to a highly inefficient level of search. As he pointed out, if someone based their reservation price on a uniform distribution while the distribution was in fact triangular on the same support he would, in expectation spend twice as much and would search five times more often than if he was correctly informed.

In our case the buyer does not know the true distribution and what is more that distribution is changing over time. To clarify ideas we can adopt an approach suggested by Rothschild (1974) in a classic paper. Since prices have to be in monetary units and they are evidently bounded it is reasonable to assume that there is a finite number, say $n$ of them. The prices $p_{1}, p_{2} \ldots p_{n}$ are arranged in ascending order and the distribution of prices is then a multinomial distribution $\Pi$ where,

$$
\Pi \in \Delta=\left\{\left(p_{1}, p_{2} \ldots p_{n}\right) \in \mathbb{R}^{n} \mid p_{i} \geqslant 0, \sum p_{i}=1\right\}
$$

Now suppose that the buyer does not know $\Pi$ but has a prior $F(\cdot)$ over $\Delta$. He then updates his prior using Bayes' rule. He does this using the information available at each time. His information consists in the number of times $N_{i}$ he has observed the 
$i$ th price, so this information can be represented by the vector,

$$
N=\left(N_{1} \ldots N_{n}\right)
$$

or more conveniently, one can think of the vector $\boldsymbol{\lambda}$ in the simplex $\Delta$ where,

$$
\lambda_{i}=\frac{N_{i}}{\sum_{j=1}^{n} N_{j}}
$$

This vector is updated in the obvious way as an observation is made. Under reasonable conditions such a process will converge to the true distribution. There are technical problems with the initial prior (see Rothschild 1974) but if the number of observations becomes sufficiently large this can be ignored. Yet, in the case in question, updating is basically limited to one day. Buyers are faced each day with a distribution that is not the same as on the previous days. Thus they are obliged to start with a relatively uninformative prior.

One answer to this problem would be to think of a situation where, on each day, the price in the outside market where the sellers obtain their stocks is either high or low. The problem of the buyer then becomes to decide whether he is sampling from a distribution with mean $\mu_{h}$ or mean $\mu_{l}$ where $\mu_{h}>\mu_{l}$.

Early in the day he is faced with a classical problem in economics that of choosing between profiting from the opportunity he is currently faced with and gaining more information by searching again. The gain in information about the distribution is offset by the potential lost opportunity if the seller no longer has stocks available. 
Here again the situation is not simple since the distribution is constantly being modified in two ways. Firstly some sellers are no longer active when they have sold all their stock and secondly as the day goes on they, in turn, modify their prices.

The situation for each buyer and seller is then reduced to two steps. Once he observes the prices or reactions he has to decide which is the prevalent distribution. Then he has to decide on his bargaining behaviour. This will be true even when the distribution of seller's prices is more degenerate. How will the buyers' reservation prices evolve over day? Those who have high reservation prices to start with will disappear from the market since they will accept offers except from very high price setters. At each successive round those who will be left in the market are buyers with initially low reservation prices faced with higher priced sellers. However, any given seller will be faced with a distribution that is being truncated from the top. Even though some buyers maybe revising their prices upwards, the distribution as a whole will be shifting down.

\subsection{The timing of negotiations}

Two things are important to note here. The information provided by our seller suggested that the larger buyers operate early in the morning and it is the case that there are proportionally more sales without negotiation in the earlier period of the market. This would be consistent with the evidence provided by Weisbuch et al. 
(2000) that large sellers typically do not "shop around" and become "locked in" to particular sellers. Many economic explanations can be given for this fact, such as the existence of implicit contracts or preferential treatment. The argument used in the paper referred to was one of simple reinforcement learning. However with one exception there is little evidence that volume decreases over the day and we will come back to this later. It might seem to be the case that as the market unwinds the negotiators would arrive at a one shot sub game perfect equilibrium and that this would remove counteroffers at the end of the day.

With the exception of local tomatoes which were never sold after 9h.30 transactions continued till the official closing time, see Figures [6 to 9, In the case of perishable goods one phenomenon that one might expect to see is a version of the ultimatum game. However no obvious distinction can be made between the behaviour of the market for oranges and that for imported tomatoes, for example.

Consider first of all the prices proposed by sellers as time passes. As can be seen from Figures 10 to 13 three different patterns emerge. The prices proposed for oranges and imported tomatoes are practically constant over the day. No trend is statistically detectable. The prices of leeks decline steadily over the day whilst local tomatoes on average are constant till $8 \mathrm{~h} .30$ and then drop sharply and become constant again at $9 \mathrm{~h}$.

[Figure 10 about here.] 
[Figure 11 about here.]

[Figure 12 about here.]

[Figure 13 about here.]

How might one set about explaining these differences? A first observation is that those products with constant prices are both imported. This means that they were bought on a large foreign wholesale market at a price that is essentially common knowledge. Each seller has a fairly precise idea of what the other sellers have paid. The state of the market in terms of the quantities available is thus not difficult to estimate. The only difficulty would come from demand side uncertainty. The stylised fact here would then be that prices for oranges and imported tomatoes would be fairly constant across the market whilst those for leeks and domestic tomatoes would vary at least at the beginning of the day. Two sided learning is taking place on the market for domestic products whilst in the other markets the learning is much more limited.

\subsection{Seller's behaviour}

For the reasons given we assume that the seller will modify his idea of the distribution of buyer's prices over the day. Given his view of this distribution he will choose the best price to offer to the buyer. Once he sees the reaction of the buyer he will revise 
his view of the distribution by truncating it at his first offer price. Of course if the buyer had a reservation price above its first offer price he would have accepted.

Assume that the seller's guess about the distribution of $x$ - that is the reservation value of the buyer - is given by the following family of density functions

$$
f(x)= \begin{cases}f_{b}+2 \frac{b-x}{b-a}\left(\frac{1}{b-a}-f_{b}\right) & \text { for } x \in[a, b] \\ 0 & \text { else }\end{cases}
$$

where

$$
f_{b} \in\left[0, \frac{1}{b-a}\right]
$$

is just $f(b)$. It is easy to check that the density function is a linear non-increasing function in $x$. If we set

$$
f_{b}=\frac{1}{b-a},
$$

then we obtain the density of the Uniform distribution. For $f_{b}=0$, we obtain the density of the Triangular distribution.

The corresponding distribution function is

$$
F(x)= \begin{cases}0 & \text { for } x<a, \\ 1-\left[f_{b}(b-x)+\left\{1-f_{b}(b-a)\right\}\left(\frac{b-x}{b-a}\right)^{2}\right] & \text { for } x \in[a, b], \\ 1 & \text { for } x>b .\end{cases}
$$




\subsubsection{Seller's offer prices}

The seller chooses the offer price to maximize his expected gain

$$
p^{*}=\arg \max (p-v)(1-F(p)) .
$$

Here, $v \in(a, b)$ denotes the reservation valuation of the seller. The first term is just his gain, given that he can strike the deal. The second term is the probability that the reservation value $x$ of the buyer is above $p$. The offer price is implicitly given by

$$
1-F\left(p^{*}\right)=\left(p^{*}-v\right) f\left(p^{*}\right)
$$

For the second order condition

$$
-2 f\left(p^{*}\right)-\left(p^{*}-v\right) f_{x}\left(p^{*}\right)<0
$$

to be fulfilled, it is sufficient that

$$
p^{*} \leqslant \frac{b+v}{2}
$$

holds. For our family of density functions this inequality always holds.

To see that (12) is sufficient, one just has to calculate the second order condition (11) for our family of density functions. It is easy to see that the second order condition is fulfilled if (12) holds. To prove that the inequality for the optimal offer price always holds, write the first order condition as

$$
f_{b}\left\{b+v-2 p^{*}\right\}+\frac{1-f_{b}(b-a)}{(b-a)^{2}}\left\{\left(b+v-2 p^{*}\right)^{2}-\left(p^{*}-v\right)^{2}\right\}=0 .
$$


Now, let us as assume firstly that

$$
f_{b} \in\left(0, \frac{1}{b-a}\right)
$$

We show, no $p$ with

$$
p \in\left(\frac{b+v}{2}, b\right]
$$

is a solution of the first order condition: when $p$ is in this range, it follows immediately that the expression in the first curly brackets of the first order condition is negative. To have a solution, the expression in the second curly brackets must be positive. However, at the lower bound $(b+v) / 2$ this expression is clearly negative. At the upper bound $b$ it is zero. Is it possible that the expression will be positive for some intermediate values? In that case, the expression must be equal to zero at least once. But we easily see that the solution for

$$
\begin{aligned}
(b+v-2 p)^{2} & =(p-v)^{2} \Leftrightarrow \\
-(b+v-2 p) & =p-v
\end{aligned}
$$

is $p=b$ (recalling that the expression on the RHS is non-positive and the expression on the LHS is non-negative). Now, what happens if $f_{b}=1 /(b-a)$ ? In that case, it is easy to see that $p^{*}=(b+v) / 2$. Eventually, for $f_{b}=0$ we have the two solutions $b$ and $(b+2 v) / 3$, where only the latter fulfils the second order condition. Thus, inequality (12) holds for $p^{*}$.

How does the optimal offer price change when $f_{b}$ increases? Total differentiation 
of the first order condition yields

$$
\frac{d p^{*}}{d f_{b}}=\frac{F_{f_{b}}\left(p^{*}\right)+\left(p^{*}-v\right) f_{f_{b}}\left(p^{*}\right)}{-2 f\left(p^{*}\right)-\left(p^{*}-v\right) f_{x}\left(p^{*}\right)}>0
$$

Let us explain how to derive the sign of this expression: the denominator is negative due to the second order condition. For the numerator we obtain after some manipulations the expression

$$
-\left[\left(1-\frac{b-p^{*}}{b-a}\right)\left(b+v-2 p^{*}\right)+\frac{b-p^{*}}{b-a}\left(p^{*}-v\right)\right]<0 .
$$

The term in the square bracket is positive: the optimal price is above $a$ and less than $b$, so that the fraction is positive and less than one. We know from (12) that $b+v-2 p^{*} \geqslant 0$. The optimal offer price must always be above the reservation value $v$ of the seller.

For our family of density functions a higher $f_{b}$ is accompanied by a lower probability mass of low reservation values and a higher probability mass for higher reservation values. A higher probability of good events makes the seller set a higher offer price.

If we calculate the optimal price for the density with the lowest mass on high reservation values (the Triangular distribution), we obtain

$$
\left.p^{*}\right|_{f_{b}=0}=\frac{b+2 v}{3}
$$

If we calculate the optimal price instead for the distribution that puts the largest 
mass on high reservation values (the Uniform distribution), we obtain

$$
\left.p^{*}\right|_{f_{b}=\frac{1}{b-a}}=\frac{b+v}{2} .
$$

Using (15), we obtain that

$$
p^{*} \in\left[\frac{b+2 v}{3}, \frac{b+v}{2}\right]
$$

where $p^{*}$ is increasing in $f_{b}$.

It is not difficult to prove that the seller always prefers higher values of $f_{b}$, because this increases his expected gain. We obtain (using the first order condition)

$$
\Pi_{f_{b}}^{*}=-\left(p^{*}-v\right) F_{f_{b}}\left(p^{*}\right)>0
$$

with

$$
F_{f_{b}}\left(p^{*}\right)=-\left(b-p^{*}\right)\left(1-\frac{b-p^{*}}{b-a}\right)<0
$$

After observing the counteroffer $c$, the seller updates his guess about the distribution of buyer's reservation value $x$. Given the seller's first offer $p^{*}$ and the buyer's counter offer $c$, the seller knows that $x \in\left[c, p^{*}\right]$. The conditional density is

$$
f\left(x \mid c \leqslant x \leqslant p^{*}\right)= \begin{cases}D^{-1}\left\{f_{b}+2 \frac{b-x}{b-a}\left(\frac{1}{b-a}-f_{b}\right)\right\} & \text { for } x \in\left[c, p^{*}\right] \\ 0 & \text { else },\end{cases}
$$

where the denominator is given as

$$
D=F\left(p^{*}\right)-F(c)
$$


We will show, that we can rewrite the above given conditional density as

$$
f\left(x \mid c \leqslant x \leqslant p^{*}\right)= \begin{cases}f_{p^{*}}+2 \frac{p^{*}-x}{p^{*}-c}\left(\frac{1}{p^{*}-c}-f_{p^{*}}\right) & \text { for } x \in\left[c, p^{*}\right] \\ 0 & \text { else },\end{cases}
$$

with

$$
f_{p^{*}}=f\left(p^{*} \mid c \leqslant x \leqslant p^{*}\right) .
$$

In that case, all results that we have derived for the optimal offer will also hold for the second offer given the family of density functions (20). First, we extend $b-x=(b-p)+(p-x)$ in the original variant of the conditional density and we obtain after deleting all equivalent terms that all we have to show is

$$
\frac{1-(b-a) f_{b}}{(b-a)^{2}}=\frac{D\left\{1-\left(p^{*}-c\right) f_{p^{*}}\right\}}{\left(p^{*}-c\right)^{2}}
$$

We show the equivalence of these two expressions by substituting for $D$ and by using

$$
-2\left(b-p^{*}\right)\left(p^{*}-c\right)+(b-c)^{2}-\left(b-p^{*}\right)^{2}=(p-c)^{2} .
$$

\section{Empirical results}

In this section, we study the movement of the seller's first and second price offers, $p_{1}^{*}$ and $p_{2}^{*}$, over the course of the trading day. How does the price setting behavior of the seller evolve during the day in the light of his previous experiences? In particular, does he react to periods of inactivity, refusals or counteroffers? Throughout, we will 
use the theoretical results derived in the previous section to interpret the empirical results.

Specifically, we employ the following variables to empirically describe the events occurring up to and at a particular point in time $t$ during any given trading day

- an (ex-post) bargaining power index $\left(I_{t}\right)$

$$
I_{t}=\frac{p_{t}-c_{t}}{p_{1, t}^{*}-c_{t}}
$$

- the relative change in the initial offer price $\left(\pi_{\text {offer }, t}\right)$

$$
\pi_{\mathrm{offer}, t} \equiv \frac{p_{1, t}^{*}-p_{1, t-1-\tau}^{*}}{p_{1, t-1-\tau}^{*}}
$$

- the relative deviation of the offer from the counteroffer $\left(\Delta_{t}\right)$

$$
\Delta_{t} \equiv \frac{p_{1, t}^{*}-c_{t}}{p_{1, t}^{*}} \geqslant 0
$$

- the number of succeeding intervals with no contact $\left(\tau_{t}\right)$

- dummy variables describing the outcome at $t\left(d_{i, t}\right)$

The ex-post measure of bargaining power $I$ is observed if, at time $t$, the seller meets a buyer, the two negotiate and strike a deal (outcome TWB in Figure 1). It relates the difference between transaction price $p$ (recall from the discussion of Figure 1 that $p=p_{2}^{*}$ in this situation) and counteroffer $c$ to the difference between the first offer $p_{1}^{*}$ and the counteroffer $c$. The index takes on values in the interval $I \in[0,1]$, 
attains its maximum if $p=p_{1}^{*}$ (when the seller prevails) and its minimum if $p=c$ (the buyer has his way).

The relative change in the initial offer price $\pi$ is simply the percentage change in $p_{1}^{*}$ relative to the last time period $(t-1-\tau$, with $\tau \geq 0)$ when $p_{1}^{*}$ was observed. The relative deviation of the offer from the counteroffer $\Delta$ measures how far apart seller and buyer have been initially if bargaining occurred.

\subsection{Seller's first price}

Starting with the seller's initial price offer $p_{1}^{*}$, the data shows no or very little movement during most days for oranges, domestic and imported tomatoes while in the market for leek $p_{1}^{*}$ fluctuates during all 15 trading days, usually moving downwards over time (as can be seen Figure 14). For this reason, we will mainly focus on the latter market in the remainder of the analysis.

[Figure 14 about here.]

[Table 7 about here.]

To parsimoniously describe the (detrended) behavior of $p_{1}^{*}$ over time we use the "inflation"-type measure $\pi_{\text {offer,t }}$ defined in (22). Table 7 shows that, in most cases, $\pi_{\text {offer, } t}$ is equal to zero. Indeed, for imported tomatoes and oranges, there are only seven occasions of non-zero price movements during all 15 days. 


\subsubsection{Explaining the movements of $p_{1}^{*}$ for leek}

In this subsection, we use linear regression to explain the behavior of $\pi_{\text {offer, } t}$ by variables capturing the preceding history of inactivity, negotiations and transactions. In the spirit of the theory of section 3.3 , the experience accumulated throughout the day leads the seller to update $f_{b}$, the parameter governing the shape of the distribution of buyers' reservation values he assumes he is be facing. Table 8 shows a contigency table for leek.

[Table 8 about here.]

For instance, periods of inactivity or series of non-cooperative buyers should lead him to decrease $f_{b}$ and - by virtue of (15) - lead to reductions in $p_{1, t}^{*}$. In the empirical model we use the number of preceding intervals with no contact, $\tau$, to capture this effect, while $\Delta_{t-1-\tau_{\Delta}}$ and $I_{t-1-\tau_{I}}$ measure the influence of the last occurrences (prior to time $t$ ) of unsuccessful and successful negotiations, respectively (where the $t-1-\tau_{\Delta}$ and $t-1-\tau_{I}$ subscripts accommodate the possibility that these last negotiations may have occurred prior to period $t-1-\tau)$. We also included dummy variables representing the outcome of the most recent meeting but only retained

$d_{O O, t-1-\tau}$ (where the "OO" subscript employs the notation of Figure 1 to indicate an "offer only" meeting). Thus, we arrived at the following regression model:

$$
\pi_{\text {offer }, t, \tau}=\beta_{0}+\beta_{1} \tau+\beta_{2} \Delta_{t-1-\tau_{\Delta}}+\beta_{3} \tilde{I}_{t-1-\tau_{I}}+\beta_{4} d_{O O, t-1-\tau}+\epsilon .
$$


This specification focuses on the influence of the more recent events on the current change in the seller's offer price. Estimates of the coefficients $\beta_{0}, \ldots, \beta_{4}$ are given in Table 9 ,

[Table 9 about here.]

The negative estimate of $\beta_{0}$ reflects the fact that, on average, $p_{1}^{*}$ moves downward. The negative sign of the coefficient of $\tau$ implies that this downward tendency is accelerated by periods of no contact. Similarly, the further apart the seller and buyer have been during previous negotiations (i.e. the larger $\Delta_{t-1-\tau_{\Delta}}$ ) the greater the seller's subsequent reduction in the initial offer price. On the other hand, the positive estimate of $\beta_{3}$ implies that preceding negotiations resulting in a transaction price close to the seller's initial offer (i.e., if $\tilde{I}_{t-1-\tau_{I}}$ is large) slow down the seller's tendency to lower $p_{1}^{*}$. Finally, the estimated negative effect of $d_{O O, t-1-\tau}$ is evidence that an "offer only" meeting in the most recent past is prompting the seller to lower the offer price.

Summing up, the estimates in Table 9 suggest that the speed with which the seller reduces $p_{1}^{*}$ during any given day is increased (decreased) if previous periods brought "bad news" ("good news"). In terms of the notation of the theory of section 3.3. "bad news" translates into a downward revision of $f_{b}$, the parameter governing the shape of the distribution of buyers' reservation values. Given this downward revision of $f_{b}$, equation (15) shows that the rational response of the seller is to lower 
$p_{1}^{*}$

\subsection{Seller's second price}

Turning to the seller's second price $p_{2}^{*}$, Figure 15 shows a downward trend over time for leek similarly to the one observed for the initial offer price. Yet, when we estimated a regression model analogous to (24) for the change in transaction prices

all coefficients were insignificant, except the one for $\tilde{I}_{t-1-\tau_{I}}$ which had the "wrong" (i.e. positive) sign. We conclude from these (unreported) results that there is a significant impact of the most recent past on the seller's initial offer price but not on his second price.

[Figure 15 about here.]

\subsection{Bargaining index}

From the discussion of Figure 1 it follows that we observe the seller's second price only if a transaction occurs, in which case $p=p_{2}^{*}$. Hence, the bargaining index of equation (21) might be written in terms of $p_{2}^{*}$ as

$$
I_{t}=\frac{p_{2, t}^{*}-c_{t}}{p_{1, t}^{*}-c_{t}}
$$

Table 10 gives summary statistics for the bargaining index for each of the four products. For each product, sample mean and median are greater or equal to 0.5. 
Hence, averaged over all negotiations and regardless of day or time of day, the transaction price (that is seller's second price) tends to be closer to the seller's initial price offer than to the buyer's counteroffer.

[Table 10 about here.]

The histograms in Figures 16 to 19, depicting the distribution of the index for each product, have mass points at $0,0.5$ and 1 . Hence, in most negotiations seller and buyer either meet exactly half way between $p_{1, t}^{*}$ and $c_{t}$ or end up at either extreme.

[Figure 16 about here.]

[Figure 17 about here.]

[Figure 18 about here.]

[Figure 19 about here.]

How does $I_{t}$ evolve during the average trading day? Pooling the data of all four products, Figure 20 shows a kernel smooth of the index with confidence intervals at the 95\% level (Härdle, 1990; Härdle et al., eds, 2000). Hence, on average, index declines during the course of the day, with episodes of a particularly rapid decline at the beginning and end of the trading day.

[Figure 20 about here.] 
How can this apparent decline in the seller's bargaining power be explained? Since our data provides plenty of information about the single seller but very little information about the many buyers he faces, we will try to explain the movement in $I_{t}$ by movements in $p_{2, t}^{*}$. This line of reasoning is aided by the fact that in the data the denominator of $I_{t}$ is fairly constant over time, see Figures 10 to 13 . We may therefore set $p_{1, t}^{*}-c_{t}=k$ and rewrite $I_{t}$ as

$$
I_{t}=1-\frac{p_{1, t}^{*}-p_{2, t}^{*}}{k} .
$$

Given that the buyer makes a counteroffer $c_{t}$, it is reasonable to assume that the second offer price will be in the interval $\left[c_{t}, p_{1, t}^{*}\right]$. For our family of density function we obtain with result (17) that

$$
p_{2, t}^{*} \in\left[\frac{p_{1, t}^{*}+2 v}{3}, \frac{p_{1, t}^{*}+v}{2}\right] .
$$

If we assume that the buyer prepared to pay higher prices leave the market early and that the ultimatum game effect comes into play then we are assuming that the seller's guess about $f_{p_{1}^{*}}$ decreases during the course of day. If we assume additionally that $\left(p_{1, t}^{*}-p_{2, t}^{*}\right)$ is increasing, then the index decreases during the day. Figure 21 clarifies the argument.

[Figure 21 about here.]

It shows the evolution of $p_{1, t}^{*}-p_{2, t}^{*}$ under the assumption that $f_{p_{1, t}^{*}}$ decreases through time. The total length of each interval from $p_{1, t}^{*}-c_{t}$ in Figure21 is $k$. The reservation 
price $v$ of the seller stays constant. As we have already discussed in detail, the first price goes down and thus $p_{1,1}^{*}>p_{1,2}^{*}>p_{1,3}^{*}$. The first interval shows $p_{2}^{*}$ for the upper bound of $f_{p_{1}^{*}}$. The second interval shows $p_{2}^{*}$ for a lower value of $f_{p_{1}^{*}}$. In that case, we know with (15) and (17) that $p_{2}^{*}$ will be lower than $\left(p_{1}^{*}+v\right) / 2$. If the difference between first price and $v$ does not shrink too much, then the difference between first price and second price increases. That is what the second line in Figure 21 shows. The same lines of reasoning can be used for the third interval.

However, given our family of density functions, simulating the index reveals that the index increases over time given a constant reservation valuation $v$ and a decreasing $f_{b}$. Here, the first price maximizes the seller's expected gain given $a, b$, $v, k$ and $f_{b}$, see equation (9). The second price maximizes the expected gain given $c=p_{1}^{*}-k, p_{1}^{*}, v$ and $f_{p_{1}^{*}}$ with the corresponding conditional density function $f(x \mid c \leqslant$ $\left.x \leqslant p_{1}^{*}\right)$. Optimal prices are calculated via numerical maximization methods. The index is then calculated with equation (26). To derive a decreasing index over time, we must allow furthermore that the reservation valuation of the seller decreases over time. In that case, a decreasing index is possible. However, it is important to mention that a decreasing $v_{t}$ suffices to generate a downward slopping index curve.

[Figure 22 about here.]

Figure 22 shows a simulated index where the reservation valuation decreases with a rate of $4.5 \%$ between succeeding intervals. Here, we have set $a=0, b=2$, 
$v_{0}=1.5$ and $k=0.75$. The density of $f_{b}$ starts with the density of the Uniform distribution - that is $f_{b}=0.5$ - and decreases over time and reaches at the end the density of the Triangular distribution with $f_{b}=0$.

\section{Conclusion}

In this paper we have analysed the effect of the bargaining process on prices. We have observations not only on the prices of transaction but also on offers and counteroffers even when no transaction took place. We first suggested a theoretical approach to the overall problem faced by the seller that we observed and then suggested a simple model to explain how the seller revised his beliefs over the day as he was faced with different buyers. The model predicted that proposed prices would decline over the day. More importantly we constructed an index of the seller's bargaining power and the model predicted that this would decline over the day. The data from the wholesale fruit and vegetable market in Marseille was consistent with these predictions. 


\section{References}

Ashenfelter, Orley C. (1989) 'How auctions work for wine and art.' Journal of Economic Perspectives 3, 23-36

Gastwirth, Joseph L. (1976) 'On probabilistic models of consumer search for information.' Quarterly Journal of Economics 90, 38-50

Grossman, Sanford J., and Motto Perry (1986) 'Sequential bargaining under asymetric information.' Journal of Economic Theory 39, 120-154

Härdle, Wolfgang (1990) Applied nonparametric regression (Cambridge: Cambridge University Press)

Härdle, Wolfgang, and Alan Kirman (1995) 'Nonclassical demand. a model-free examination of price-quantity relations in the marseille fish market.' Journal of Econometrics 67, 227-257

Härdle, Wolfgang, Sigbert Klinke, and Marlene Müller, eds (2000) XploRe Learning Guide (Berlin: Springer-Verlag)

McAfee, R. Preston, and Daniel Vincent (1993) 'The declining price anomaly.' Journal of Economic Theory 60, 191-212

Myerson, Roger B., and Mark A. Satterthwaite (1983) 'Efficient mechanisms for bilateral trading.' Journal of Economic Theory 29, 265-281 
Pezanis-Christou, Paul (1997) 'Sequential auctions with supply uncertainty.' Working Paper

Rothschild, Michael (1974) 'Searching for the lowest price when the distribution of prices is unknown.' Journal of Political Economy 82, 689-712

Rubinstein, Ariel (1982) 'Perfect equilibrium in a bargaining model.' Econometrica 50, 97-109

Weisbuch, Gérard, Alan Kirman, and Dorothea Herreiner (2000) 'Market organization and trading relationships.' Economic Journal 110, 411-436 


\section{List of Figures}

$1 \quad$ How a meeting between seller and buyer may evolve . . . . . . . . . . 36

2 Product leek. Average number of contacts and negotiations during the course of the day . . . . . . . . . . . . . . 37

$3 \quad$ Product domestic tomatoes. Average number of contacts and negotiations during the course of the day . . . . . . . . . . . . 38

$4 \quad$ Product imported tomatoes. Average number of contacts and negotiations during the course of the day . . . . . . . . . . . . . . . 39

5 Product oranges. Average number of contacts and negotiations during the course of the day . . . . . . . . . . . . . . . . 40

$6 \quad$ Product leek. Fraction of meetings with counteroffers . . . . . . . . . 41

$7 \quad$ Product domestic tomatoes. Fraction of meetings with counteroffers . 42

8 Product imported tomatoes. Fraction of meetings with counteroffers. 43

$9 \quad$ Product oranges. Fraction of meetings with counteroffers . . . . . . . 44

$10 \quad$ Product leek. Average offer, transaction price, and counteroffer . . . 45

11 Product domestic tomatoes. Average offer, transaction price, and

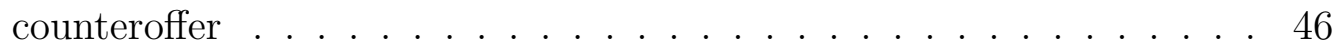

12 Product imported tomatoes. Average offer, transaction price, and

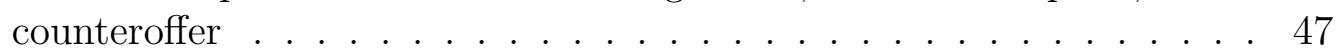

13 Product oranges. Average offer, transaction price, and counteroffer . 48

14 Behaviour of initial offer prices for leek over time . . . . . . . . . . . 49

15 $\quad$ Behaviour of transaction prices for leek over time . . . . . . . . . . . 50

16 Frequency of the bargaining power index for leek . . . . . . . . . . . 51

17 Frequency of the bargaining power index for domestic tomatoes . . . 52

18 Frequency of the bargaining power index for imported tomatoes . . . 53

19 Frequency of the bargaining power index for oranges . . . . . . . . . 54

20 Smoothed bargaining power index . . . . . . . . . . . . . . . 55

$21 \quad$ Relation between first and second price . . . . . . . . . . . . . . . . 56

$22 \quad$ Simulated bargaining power index . . . . . . . . . . . . . . . . 57 


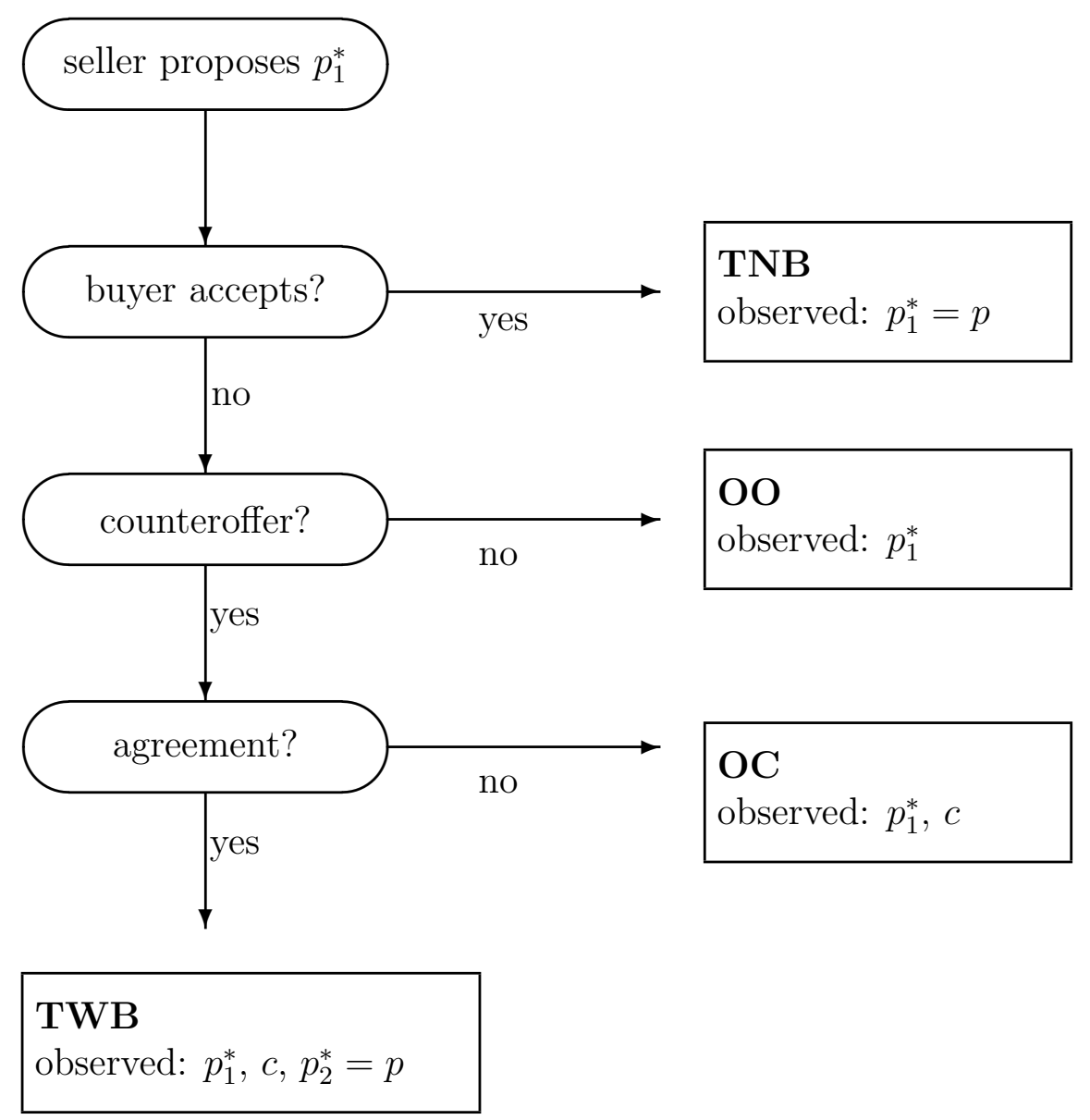

Figure 1: How a meeting between seller and buyer may evolve. The abbreviations are transaction with no bargaining (TNB), offer only (OO), offer and counteroffer (OC), and transaction with bargaining $(T W B) . p_{1}^{*}$ is seller's initial offer price, $c$ is buyer's counteroffer, $p_{2}^{*}$ is seller's second offer price and $p$ is the transaction price. 


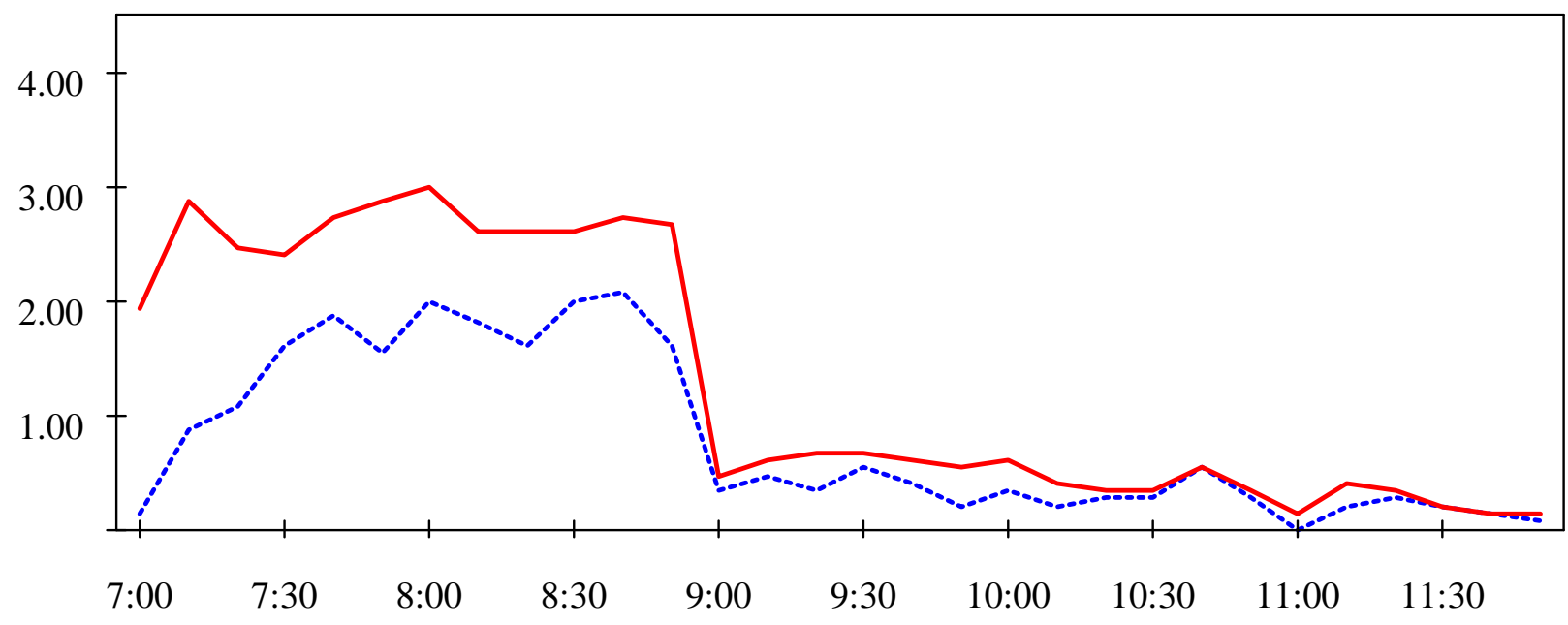

Figure 2: Product leek. Average number of contacts (upper solid) and negotiations (lower dashed) during the course of the day. 


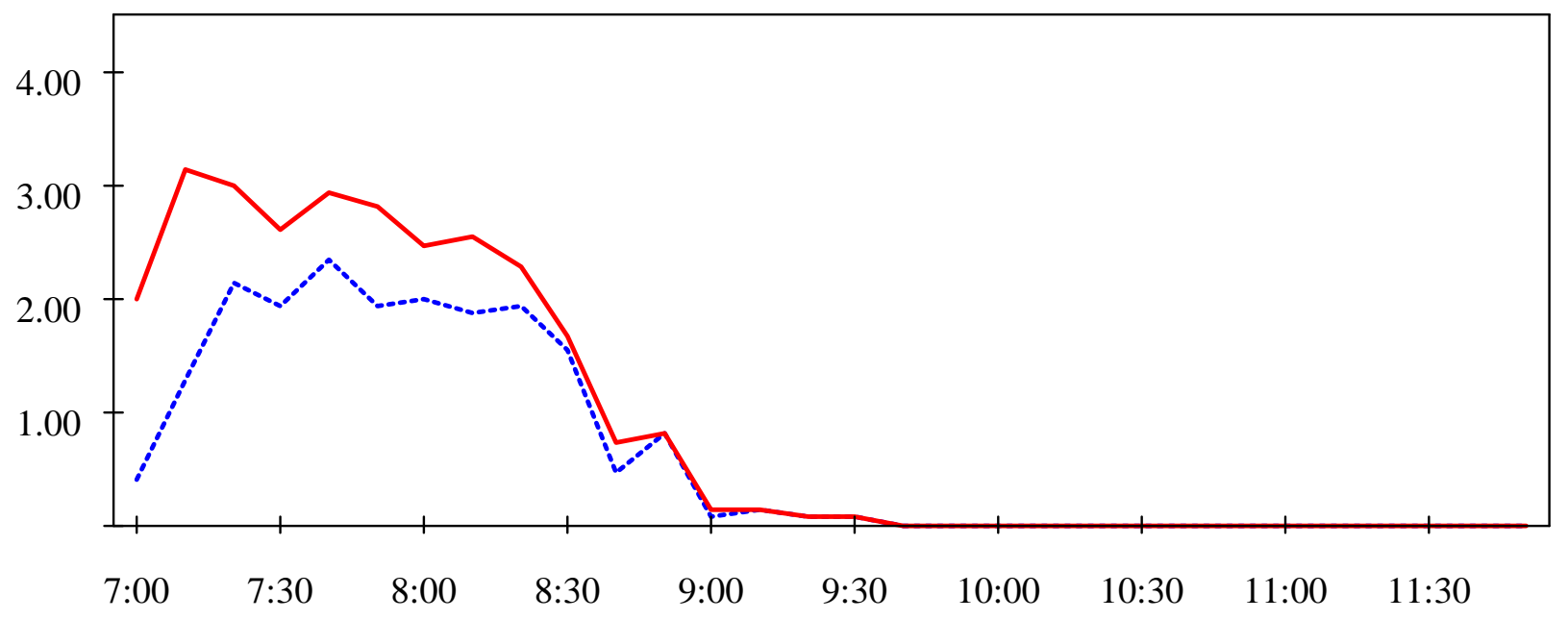

Figure 3: Product domestic tomatoes. Average number of contacts (upper solid) and negotiations (lower dashed) during the course of the day. 


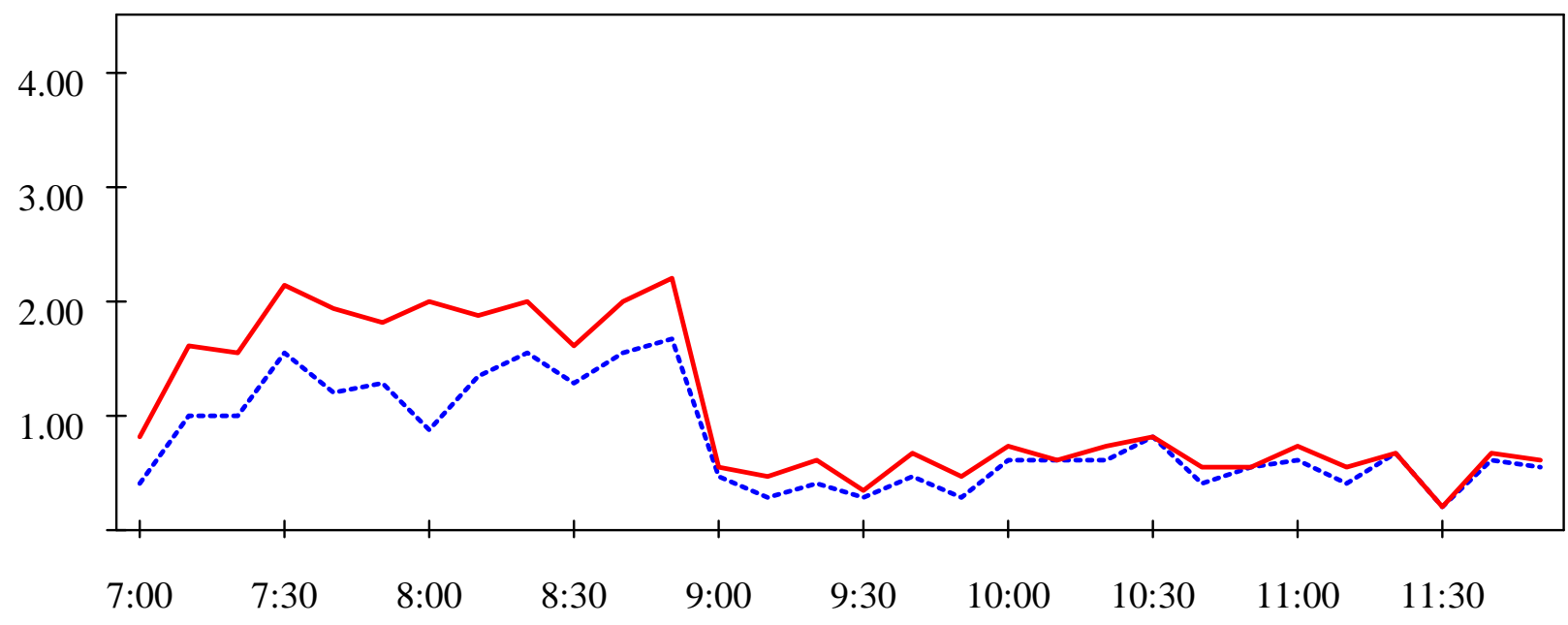

Figure 4: Product imported tomatoes. Average number of contacts (upper solid) and negotiations (lower dashed) during the course of the day. 


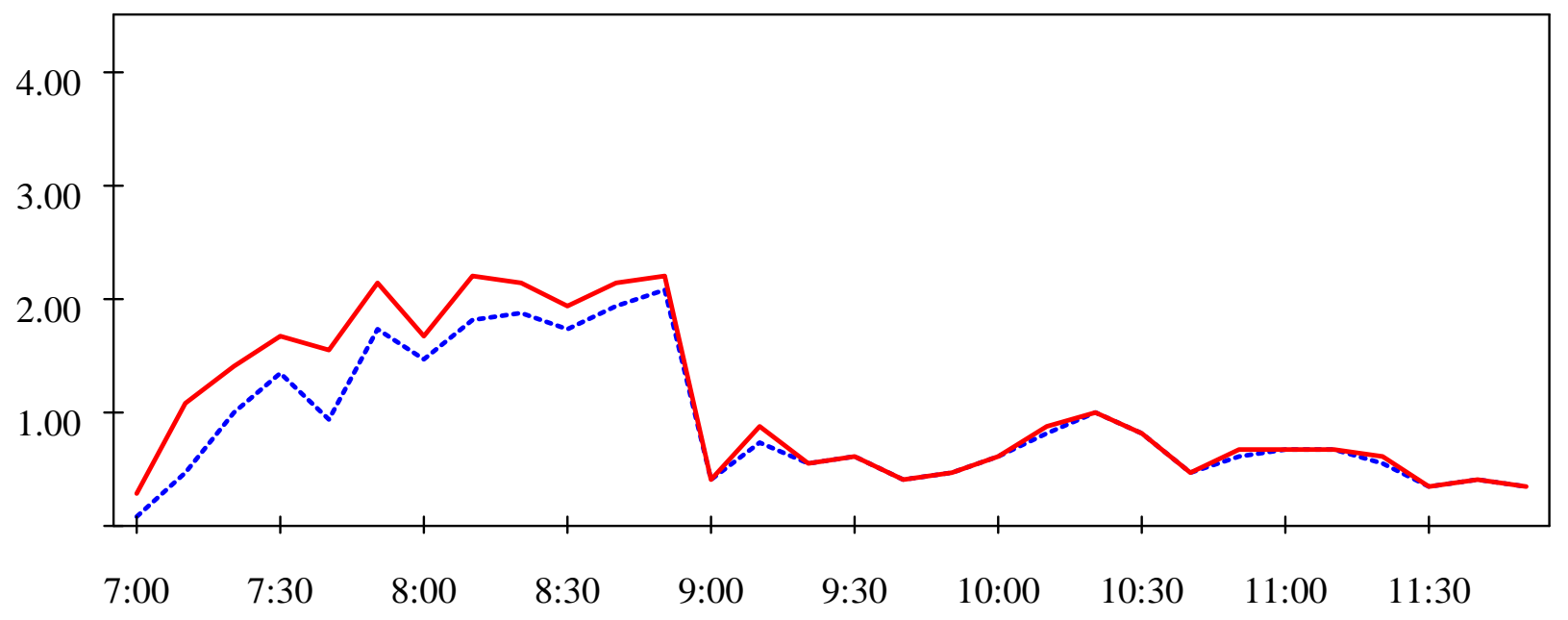

Figure 5: Product oranges. Average number of contacts (upper solid) and negotiations (lower dashed) during the course of the day. 


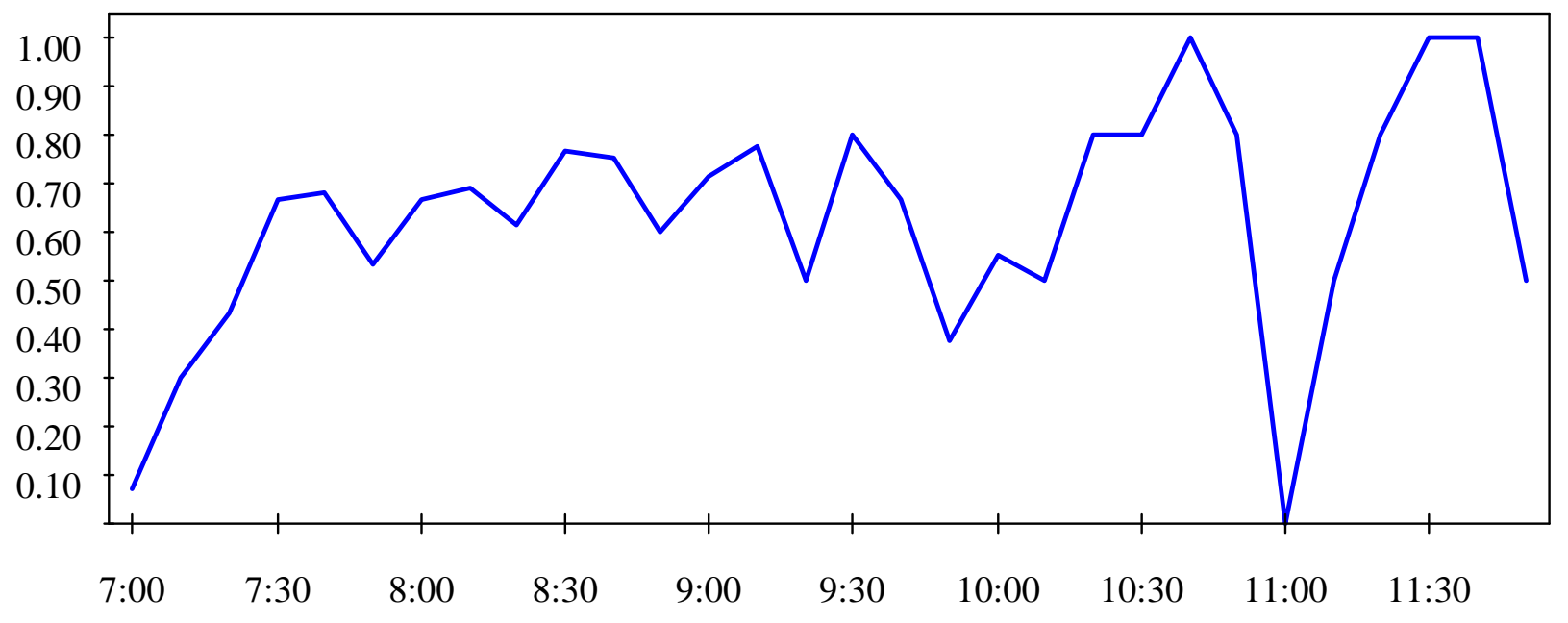

Figure 6: Product leek. Fraction of meetings with counteroffers of buyers. 


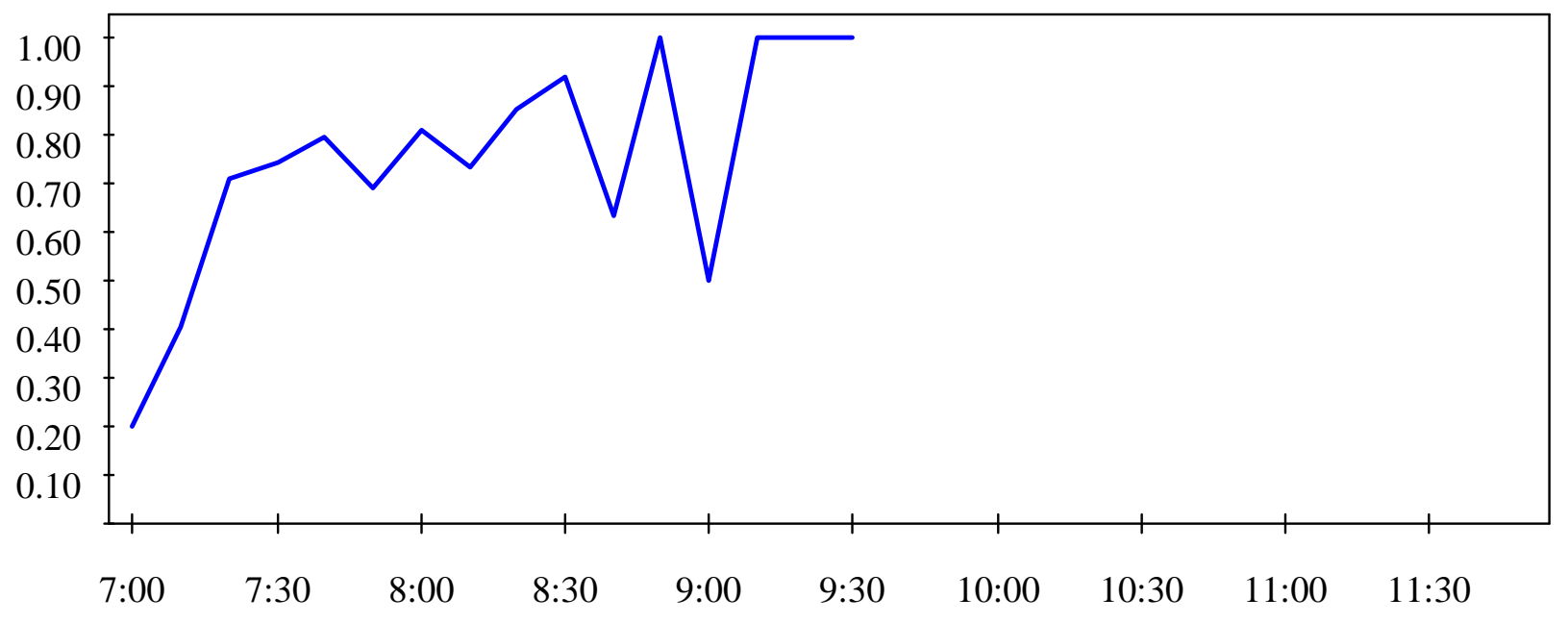

Figure 7: Product domestic tomatoes. Fraction of meetings with counteroffers of buyers. 


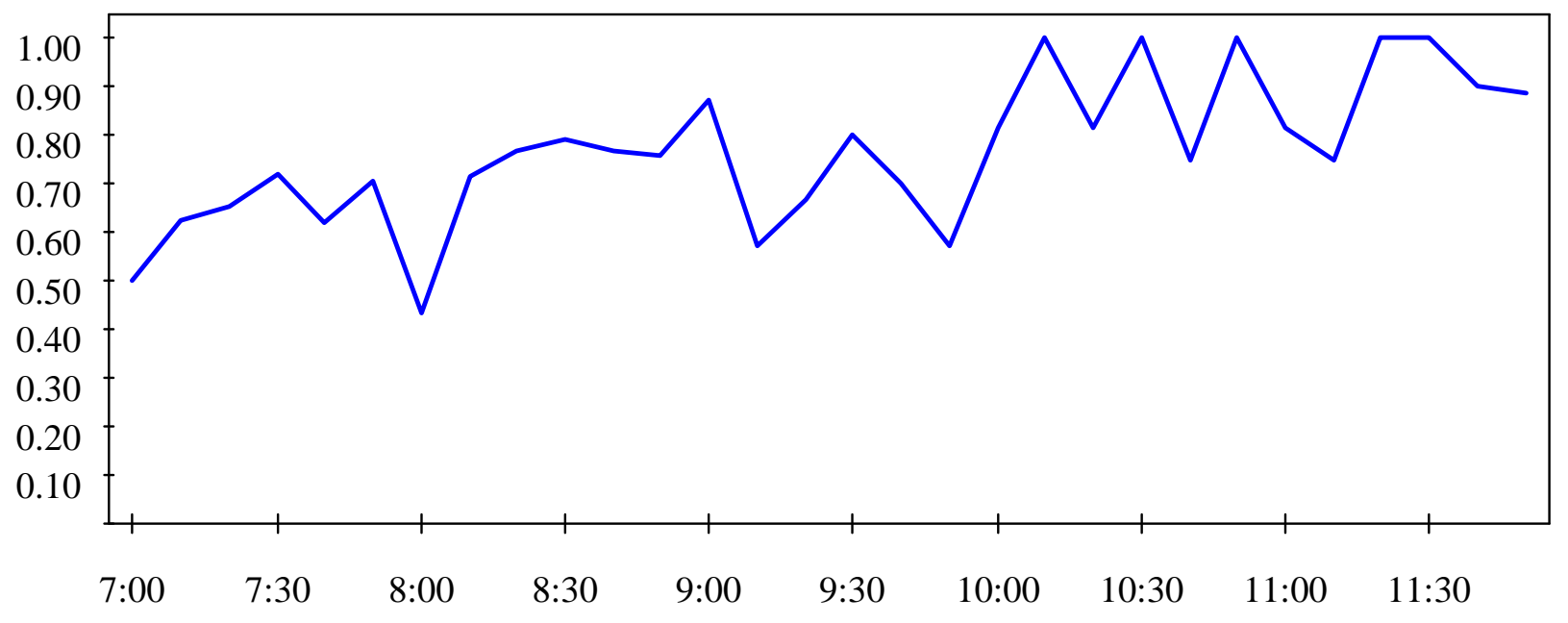

Figure 8: Product imported tomatoes. Fraction of meetings with counteroffers of buyers. 


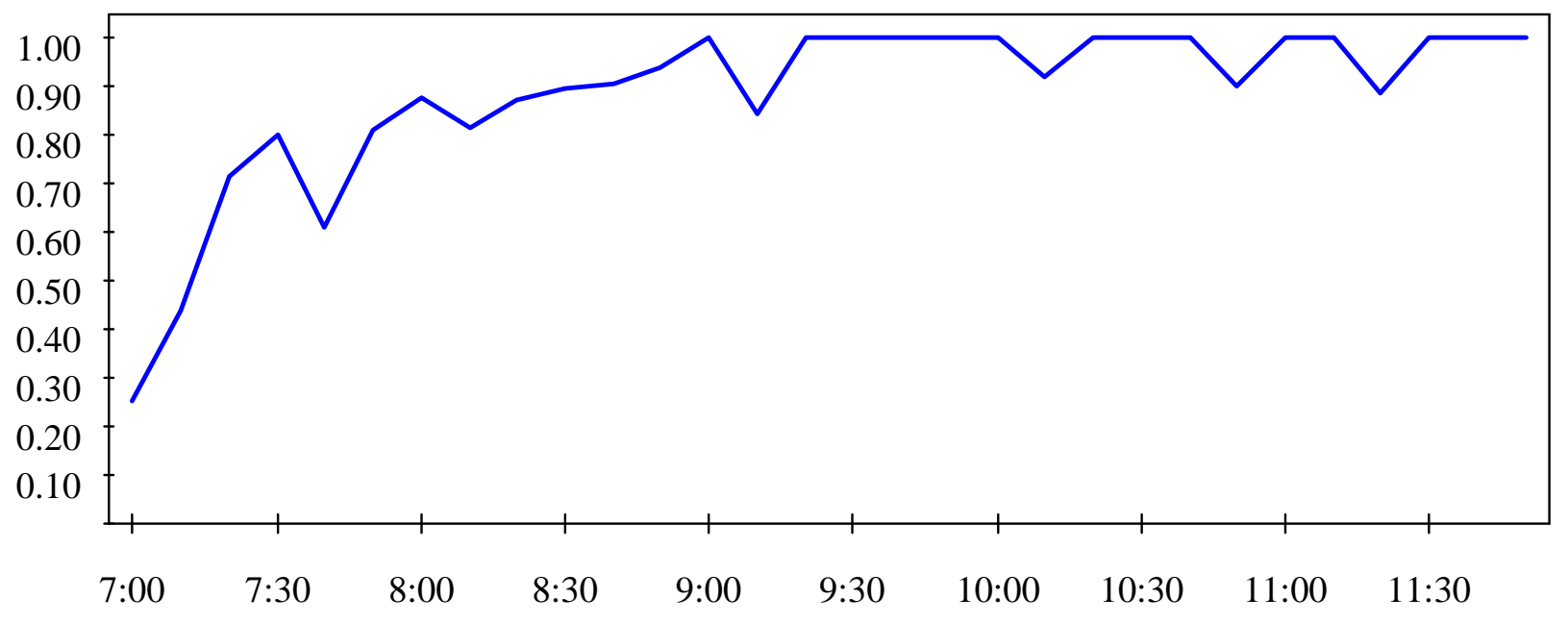

Figure 9: Product oranges. Fraction of meetings with counteroffers of buyers. 


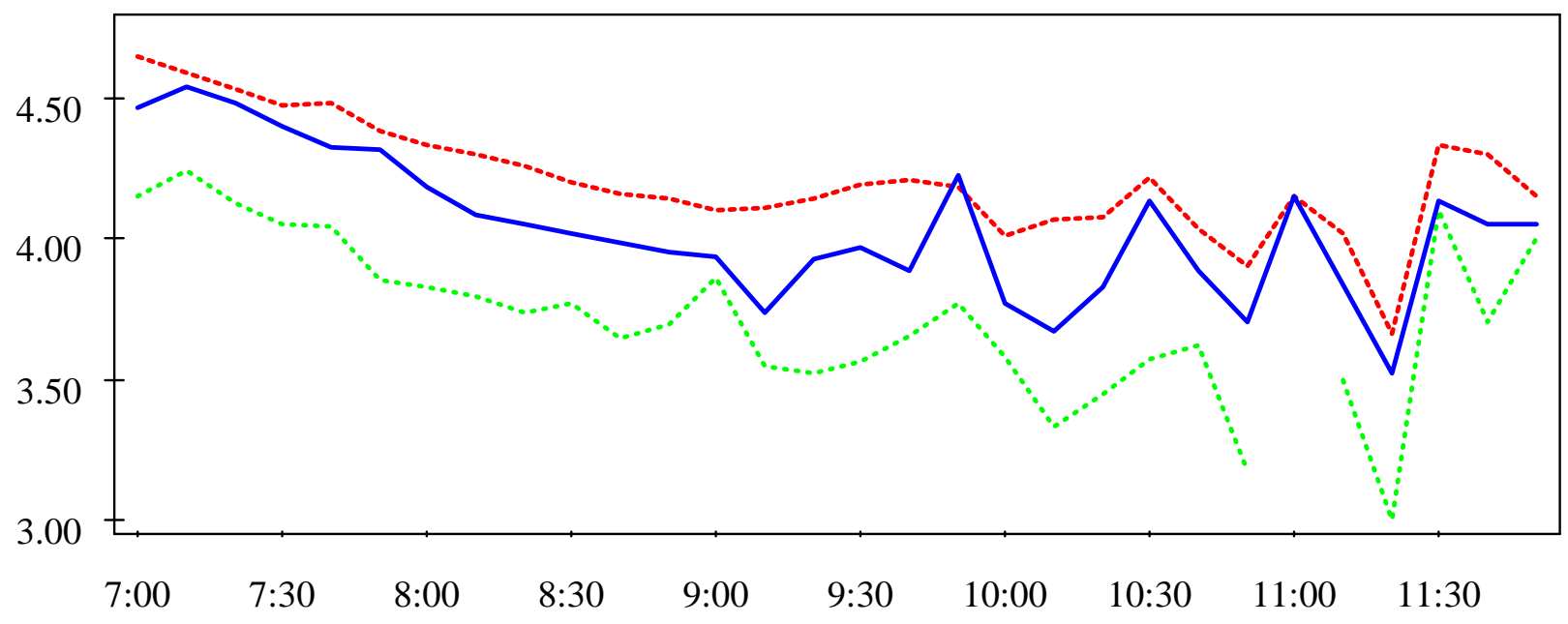

Figure 10: Product leek. Average offer (upper dashed), transaction price (middle solid), and counteroffer (lower dotted). 


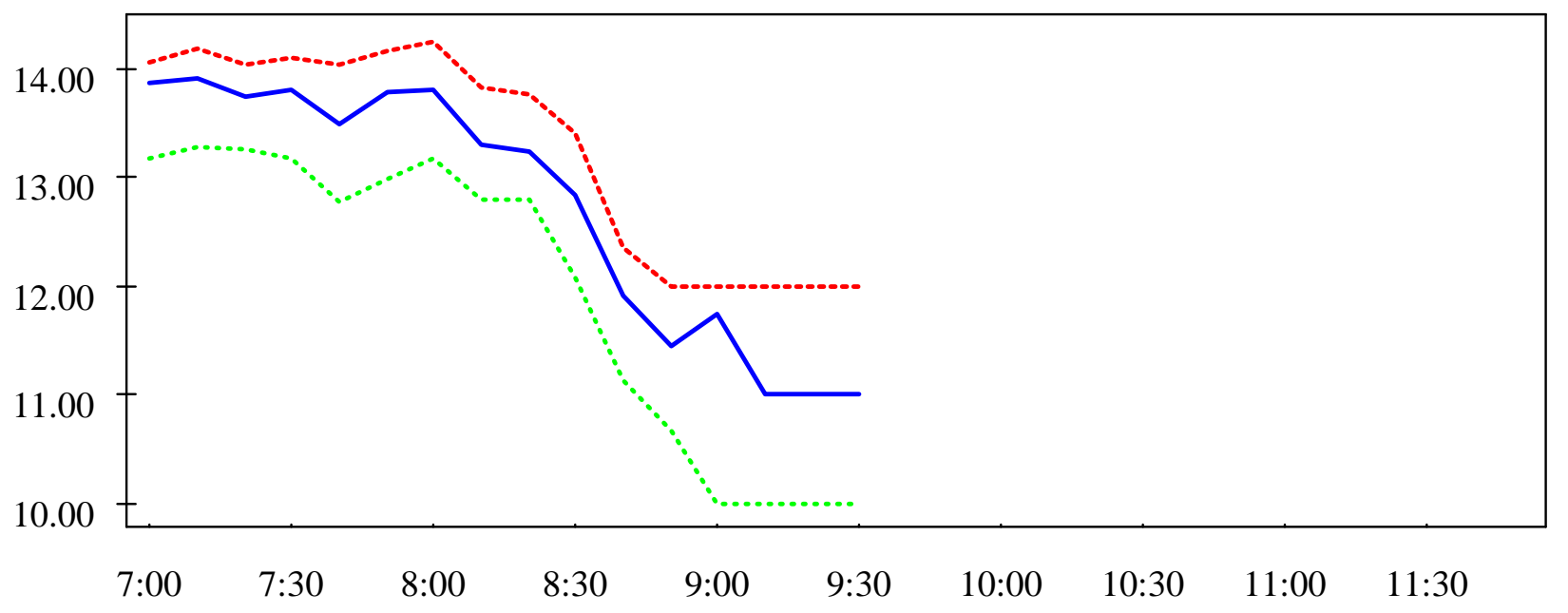

Figure 11: Product domestic tomatoes. Average offer (upper dashed), transaction price (middle solid), and counteroffer (lower dotted). 


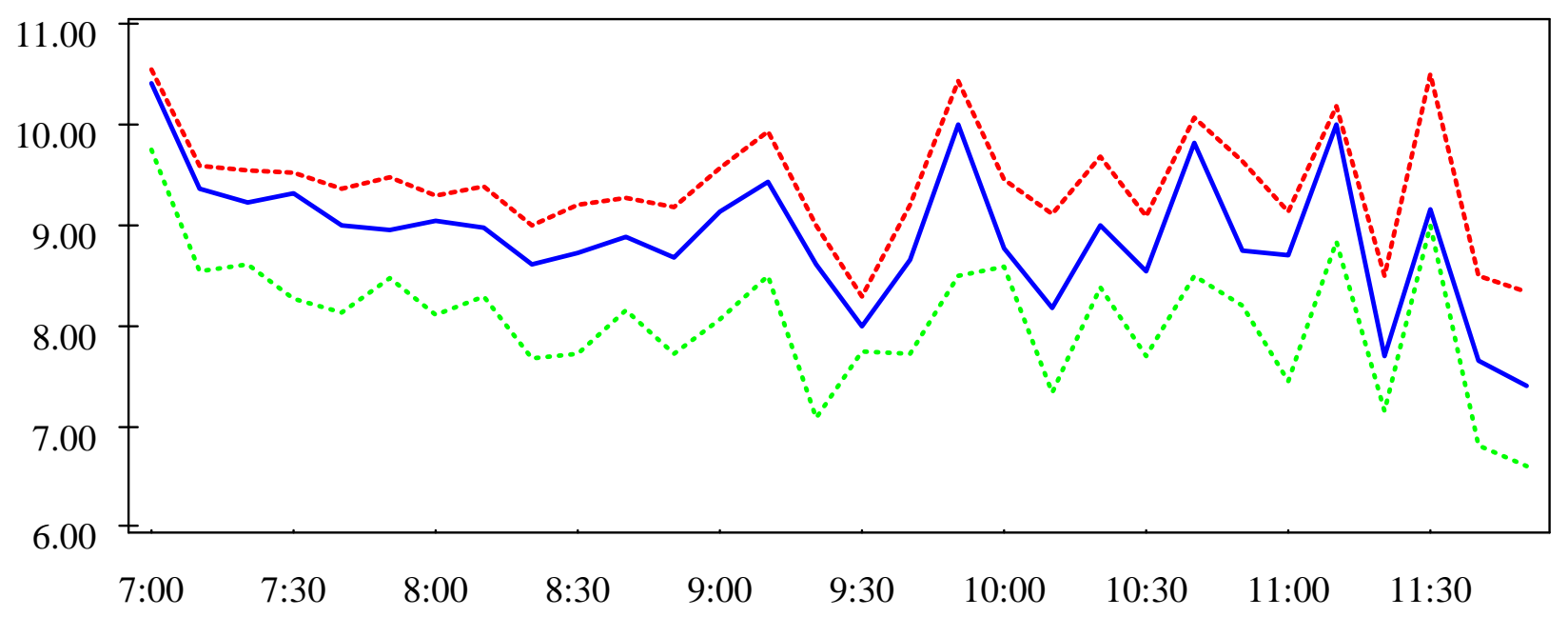

Figure 12: Product imported tomatoes. Average offer (upper dashed), transaction price (middle solid), and counteroffer (lower dotted). 


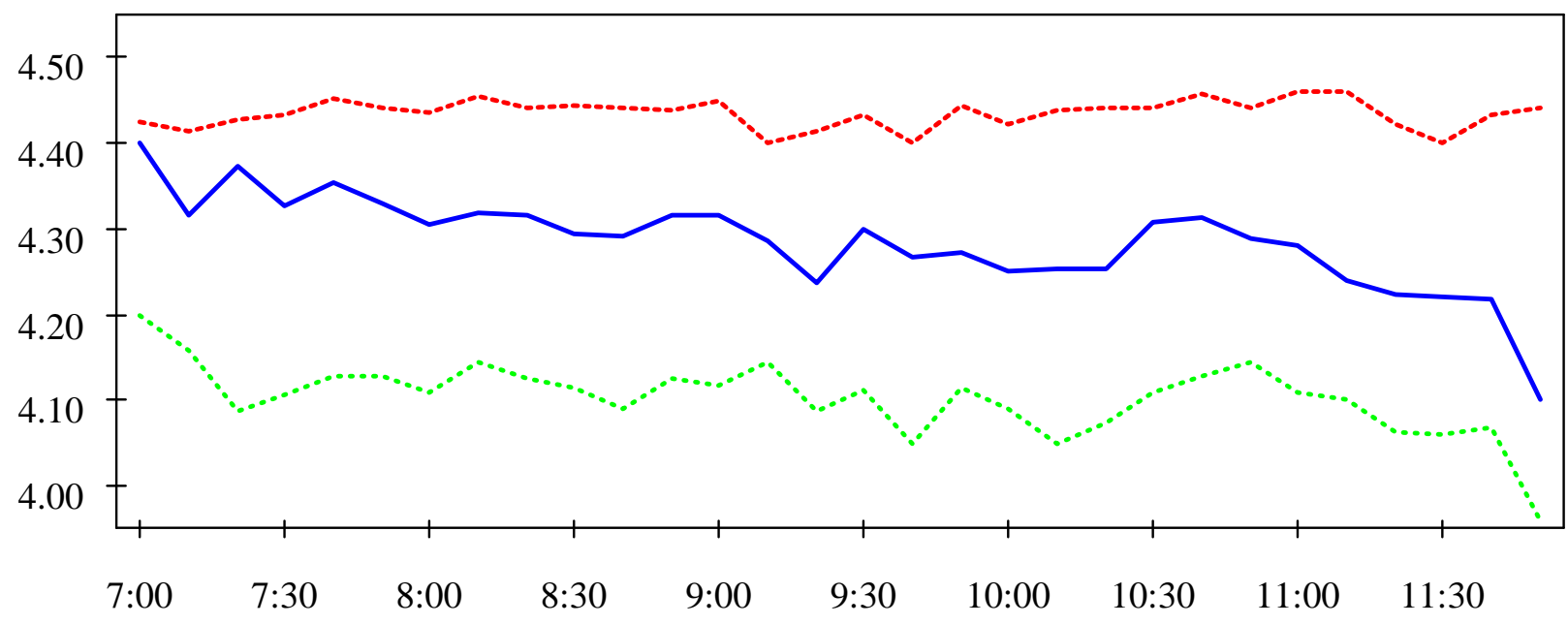

Figure 13: Product oranges. Average offer (upper dashed), transaction price (middle solid), and counteroffer (lower dotted). 


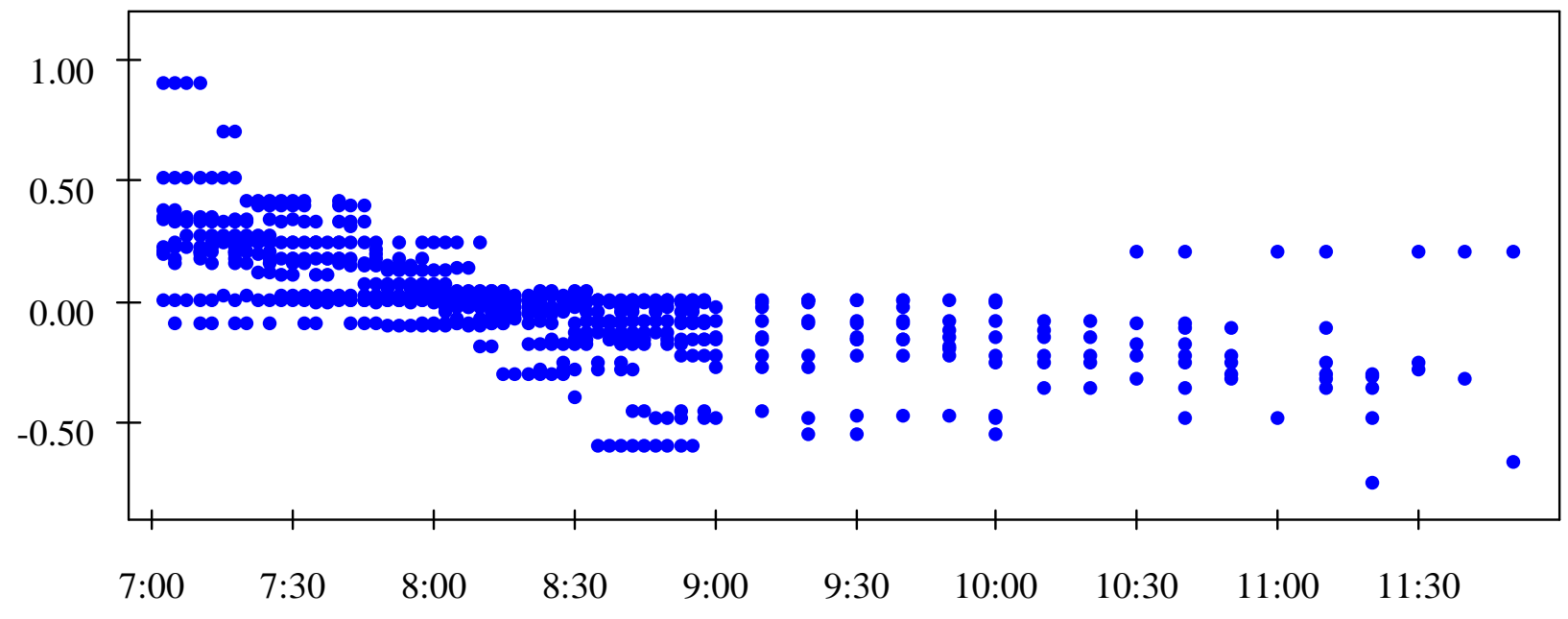

Figure 14: Behaviour of initial offer prices for leek over time (as deviations from their daily average). 


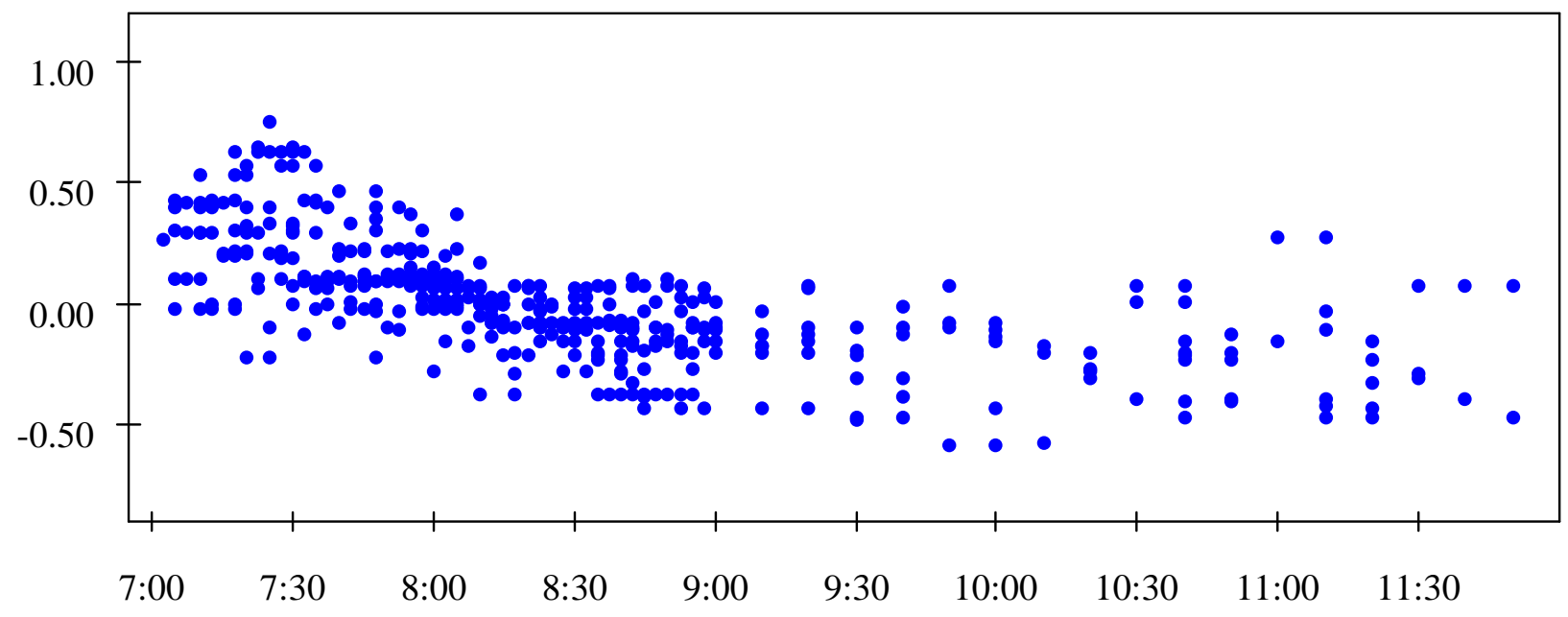

Figure 15: Behaviour of transaction prices for leek over time (as deviations from their daily average). 


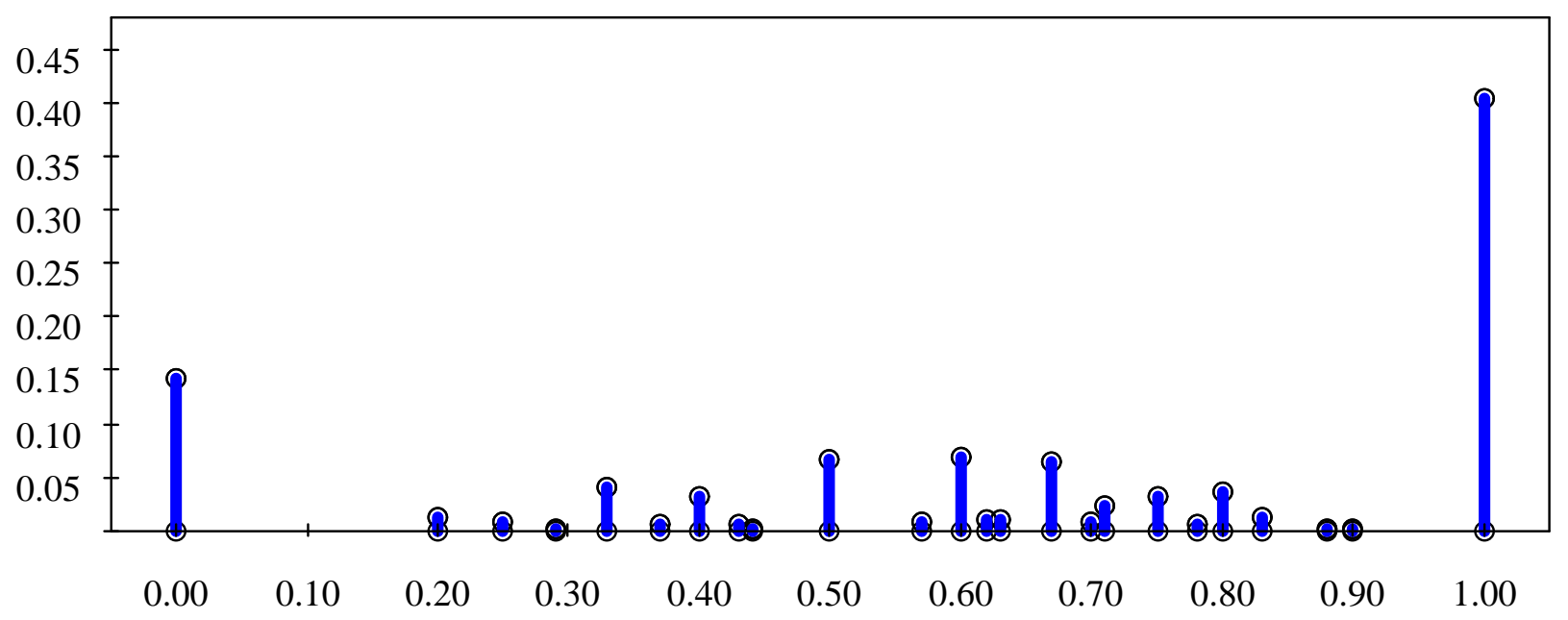

Figure 16: Frequency of the bargaining power index for leek. The bargaining index measures the relative deviation between transaction price and counteroffer with respect to the difference between initial offer price and counteroffer, see also equation (21). 


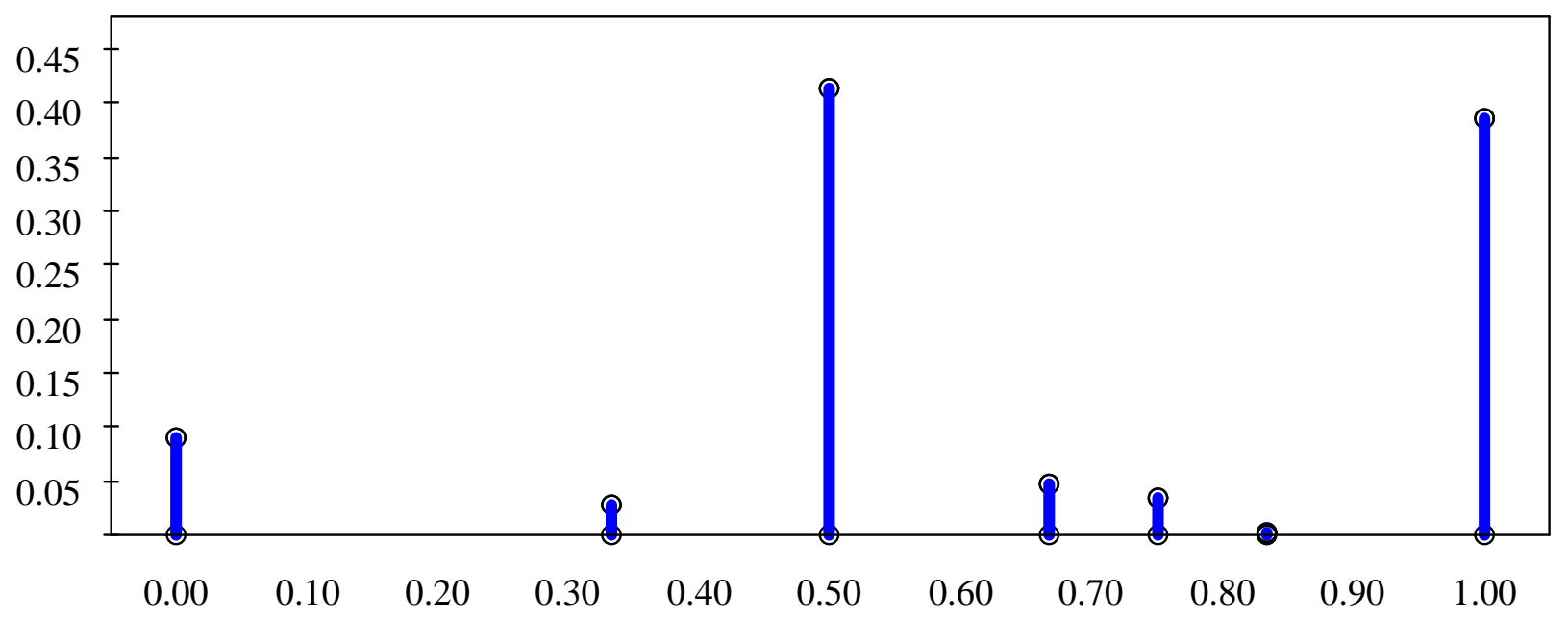

Figure 17: Frequency of the bargaining power index (21) for domestic tomatoes. The bargaining index measures the relative deviation between transaction price and counteroffer with respect to the difference between initial offer price and counteroffer, see also equation (21). 


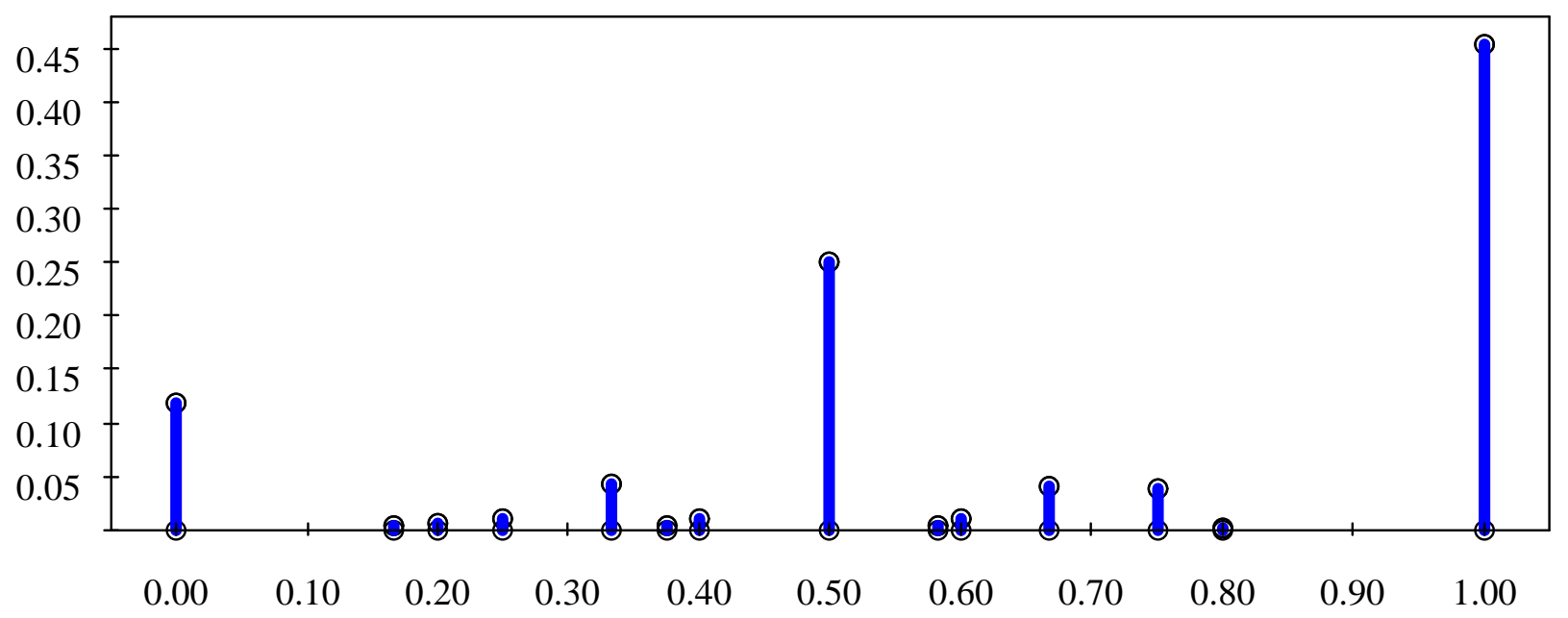

Figure 18: Frequency of the bargaining power index (21) for imported tomatoes. The bargaining index measures the relative deviation between transaction price and counteroffer with respect to the difference between initial offer price and counteroffer, see also equation (21). 


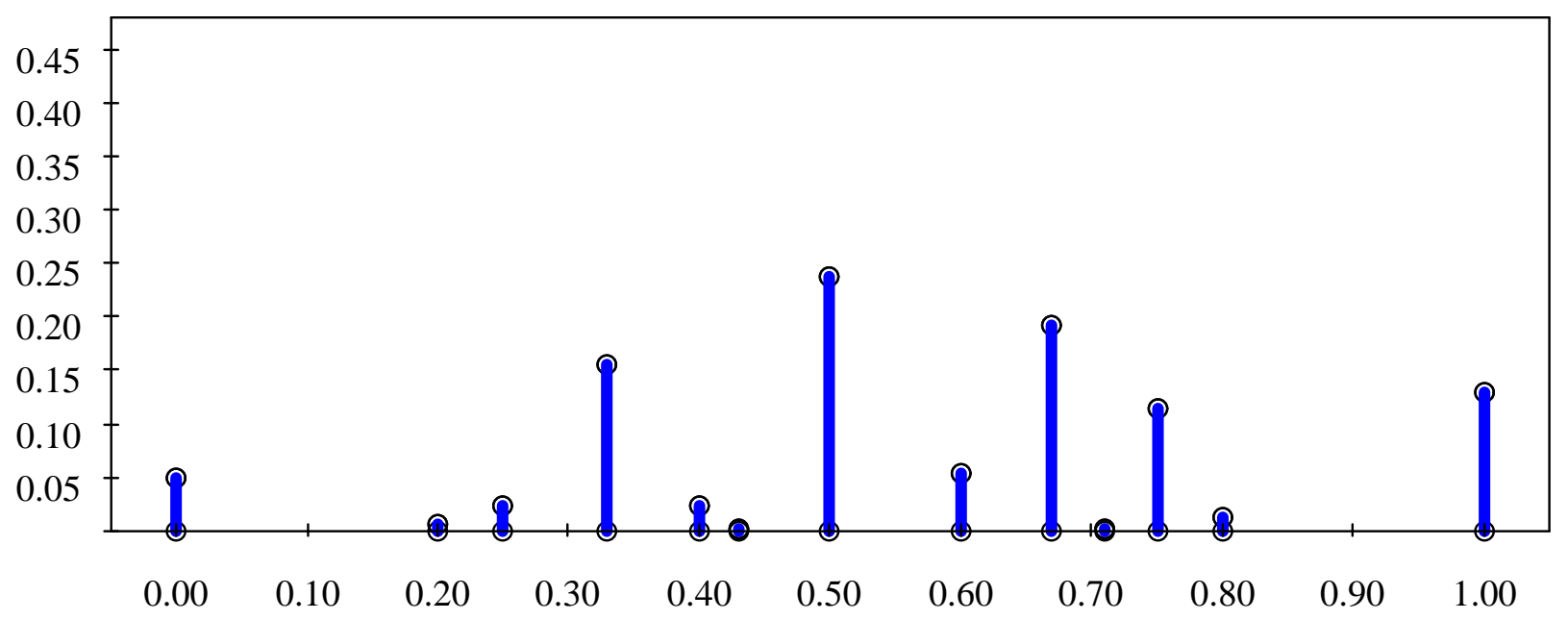

Figure 19: Frequency of the bargaining power index (21) for oranges. The bargaining index measures the relative deviation between transaction price and counteroffer with respect to the difference between initial offer price and counteroffer, see also equation (21). 


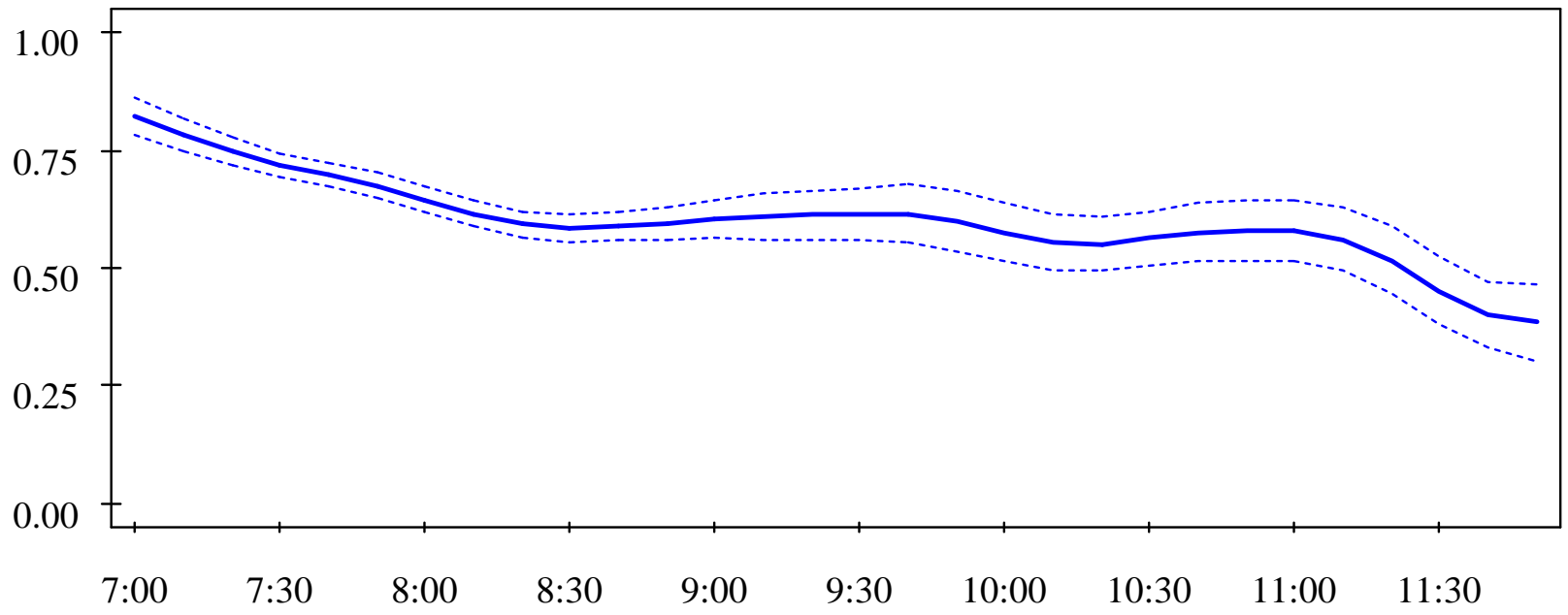

Figure 20: Smoothed bargaining power index. The bargaining index measures the relative deviation between transaction price and counteroffer with respect to the difference between initial offer price and counteroffer, see also equation (21). Confidence intervals at the 95\% level. 


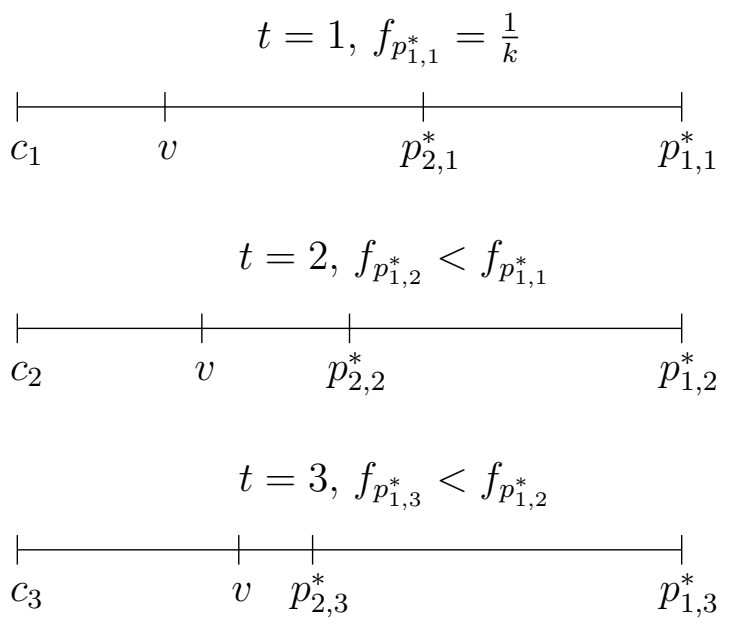

Figure 21: Relation between first and second price given a decreasing density $f$ of buyers with high reservation prices. $p_{1}^{*}$ is seller's initial offer price, $c$ is buyer's counteroffer, $v$ is seller's constant reservation valuation and $p_{2}^{*}$ is the transaction price. The figure illustrates the special case where the bargaining index goes down. 


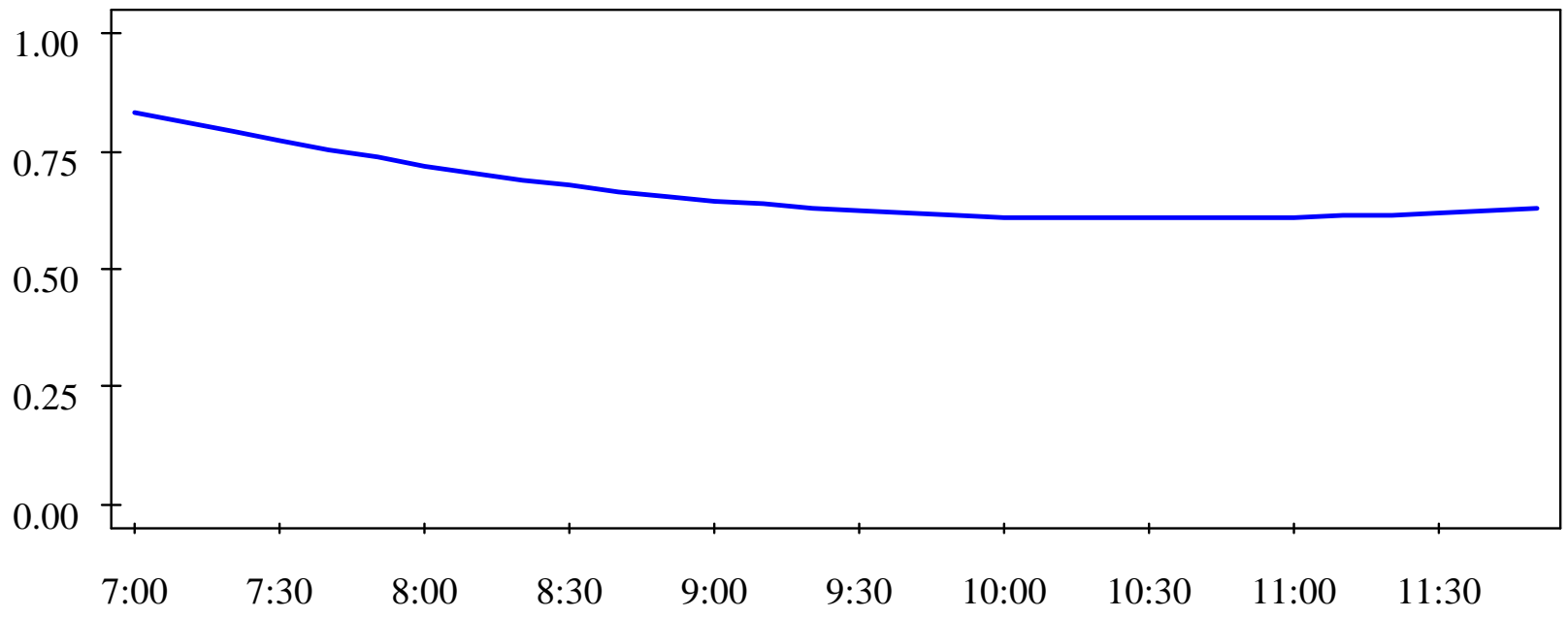

Figure 22: Simulated bargaining power index, where both $f$-that is the density of buyers with maximal reservation price-and seller's reservation valuation $v$ decrease over time. 


\section{List of Tables}

$1 \quad$ Whole database: relative frequency of the categories for the different sorts of vegetables (in percent) . . . . . . . . . . . 59

2 Whole database: relative frequency of the categories for the different sorts of vegetables given that contact took place (in percent) . . . . . 60

3 Observations from 7 to 9 o'clock: relative frequency of the categories for the different sorts of vegetables (in percent) . . . . . . . . . 61

4 Observations from 7 to 9 o'clock: relative frequency of the categories for the different sorts of vegetables given that contact took place (in

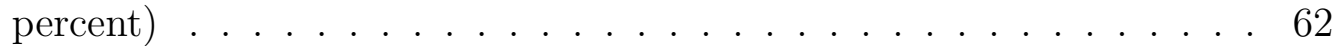

5 Observations from 9 to 12 o'clock: relative frequency of the categories for the different sorts of vegetables (in percent) . . . . . . . . . 63

6 Observations from 9 to 12 o'clock: relative frequency of the categories for the different sorts of vegetables given that contact took place (in

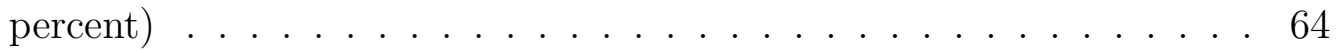

$7 \quad$ Summary statistics for the relative changes in current offer prices with respect to previously observed offer prices . . . . . . . . . . . 65

8 Contingency table for leek: relative price changes in initial offer prices

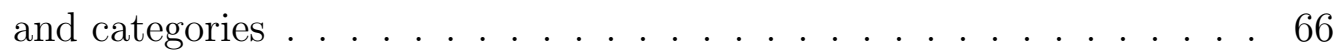

$9 \quad$ Explaining the behavior of the relative change in the initial offer price for leek with a linear regression [ . . . . . . . . . . . . 67

10 Summary statistics for the realizations of the bargaining power index for the different products . . . . . . . . . . . . . . . 68 
Table 1: Whole database: relative frequency of the categories for the different sorts of vegetables (in percent). Every trading day is divided into time grids. From 7 to 9 o'clock, the length of the grid is 2 minutes 30 seconds. From 9 to 12 o'clock, the length of the grid is 10 minutes. The categories describe the way in which a meeting between seller and buyer in a time grid might unfold. If no buyer shows up, no contact happened. If a buyer shows up, the seller makes an initial offer price which is either accepted (transaction no bargaining) or rejected. Offer only happens if the buyer rejects the initial offer and walks away. Offer and counteroffer happens if the buyer responds the initial offer with a counteroffer that is rejected by the seller. Transaction with bargaining happens if the buyer responds the initial offer with a counteroffer and both parties agree on a transaction price.

\begin{tabular}{lccccc}
\hline \hline & & \multicolumn{4}{c}{ contact } \\
\cline { 3 - 6 } & & & & \multicolumn{2}{c}{ transaction } \\
\cline { 3 - 6 } & & & offer and & no bar- & bar- \\
leek & no contact & offer only & counteroffer & gaining & gaining \\
\cline { 2 - 6 } domestic tomatoes & 41.11 & 11.62 & 5.96 & 12.22 & 29.09 \\
imported tomatoes & 58.59 & 1.72 & 0.51 & 11.01 & 28.18 \\
oranges & 51.72 & 1.11 & 0.61 & 11.92 & 34.65 \\
\hline \hline
\end{tabular}


Table 2: Whole database: relative frequency of the categories for the different sorts of vegetables given that contact took place (in percent). Every trading day is divided into time grids. From 7 to 9 o'clock, the length of the grid is 2 minutes 30 seconds. From 9 to 12 o'clock, the length of the grid is 10 minutes. If a buyer shows up, the seller makes an initial offer price which is either accepted (transaction no bargain) or rejected. Offer only happens if the buyer rejects the initial offer and walks away. Offer and counteroffer happens if the buyer responds the initial offer with a counteroffer that is rejected by the seller. Transaction with bargaining happens if the buyer responds the initial offer with a counteroffer and both parties agree on a transaction price.

\begin{tabular}{lcccc}
\hline \hline & & & \multicolumn{2}{c}{ transaction } \\
\cline { 3 - 5 } & & offer and & & \\
& offer only & counteroffer & no bargaining & bargaining \\
\cline { 2 - 5 } leek & 19.73 & 10.12 & 20.75 & 49.40 \\
domestic tomatoes & 4.15 & 1.22 & 26.59 & 68.05 \\
imported tomatoes & 2.30 & 1.26 & 24.69 & 71.76 \\
oranges & 2.37 & 1.94 & 11.40 & 84.30 \\
\hline \hline
\end{tabular}


Table 3: Observations from 7 to 9 o'clock: relative frequency of the categories for the different sorts of vegetables (in percent). The categories describe the way in which a meeting between seller and buyer in a time grid might unfold. If no buyer shows up, no contact happened. If a buyer shows up, the seller makes an initial offer price which is either accepted (transaction no bargaining) or rejected. Offer only happens if the buyer rejects the initial offer and walks away. Offer and counteroffer happens if the buyer responds the initial offer with a counteroffer that is rejected by the seller. Transaction with bargaining happens if the buyer responds the initial offer with a counteroffer and both parties agree on a transaction price.

\begin{tabular}{lccccc}
\hline \hline & & \multicolumn{4}{c}{ contact } \\
\cline { 3 - 6 } & & & & \multicolumn{2}{c}{ transaction } \\
\cline { 3 - 6 } leek & & offer and & no bar- & bar- \\
no contact & offer only & counteroffer & gaining & gaining \\
\cline { 3 - 6 } domestic tomatoes & 34.44 & 13.61 & 6.81 & 14.17 & 30.97 \\
imported tomatoes & 31.99 & 2.86 & 0.84 & 18.18 & 46.13 \\
oranges & 55.28 & 1.39 & 0.69 & 12.92 & 29.72 \\
\hline \hline
\end{tabular}


Table 4: Observations from 7 to 9 o'clock: relative frequency of the categories for the different sorts of vegetables given that contact took place (in percent). If a buyer shows up, the seller makes an initial offer price which is either accepted (transaction no bargain) or rejected. Offer only happens if the buyer rejects the initial offer and walks away. Offer and counteroffer happens if the buyer responds the initial offer with a counteroffer that is rejected by the seller. Transaction with bargaining happens if the buyer responds the initial offer with a counteroffer and both parties agree on a transaction price.

\begin{tabular}{lcccc}
\hline \hline & & \multicolumn{2}{c}{ transaction } \\
\cline { 3 - 5 } leek & offer and & & \\
domestic tomatoes & 4.21 & 10.38 & 21.61 & 47.25 \\
imported tomatoes & 3.11 & 1.24 & 26.73 & 67.82 \\
oranges & 3.61 & 2.55 & 28.88 & 66.46 \\
\hline \hline
\end{tabular}


Table 5: Observations from 9 to 12 o'clock: relative frequency of the categories for the different sorts of vegetables (in percent). The categories describe the way in which a meeting between seller and buyer in a time grid might unfold. If no buyer shows up, no contact happened. If a buyer shows up, the seller makes an initial offer price which is either accepted (transaction no bargaining) or rejected. Offer only happens if the buyer rejects the initial offer and walks away. Offer and counteroffer happens if the buyer responds the initial offer with a counteroffer that is rejected by the seller. Transaction with bargaining happens if the buyer responds the initial offer with a counteroffer and both parties agree on a transaction price.

\begin{tabular}{lccccc}
\hline \hline & & \multicolumn{4}{c}{ contact } \\
\cline { 3 - 6 } & & & \multicolumn{2}{c}{ transaction } \\
\cline { 3 - 6 } & & & offer and & no bar- & bar- \\
leek & no contact & offer only & counteroffer & gaining & gaining \\
\cline { 3 - 6 } domestic tomatoes & 59.22 & 6.67 & 3.53 & 6.67 & 23.92 \\
imported tomatoes & 98.98 & 0.00 & 0.00 & 0.00 & 1.02 \\
oranges & 41.96 & 0.39 & 0.39 & 9.41 & 47.84 \\
\hline \hline
\end{tabular}


Table 6: Observations from 9 to 12 o'clock: relative frequency of the categories for the different sorts of vegetables given that contact took place (in percent). If a buyer shows up, the seller makes an initial offer price which is either accepted (transaction no bargain) or rejected. Offer only happens if the buyer rejects the initial offer and walks away. Offer and counteroffer happens if the buyer responds the initial offer with a counteroffer that is rejected by the seller. Transaction with bargaining happens if the buyer responds the initial offer with a counteroffer and both parties agree on a transaction price.

\begin{tabular}{lcccc}
\hline \hline & & \multicolumn{2}{c}{ transaction } \\
\cline { 3 - 5 } & & offer and & & \\
leek & offer only & counteroffer & no bargaining & bargaining \\
\cline { 2 - 5 } domestic tomatoes & 0.00 & 8.65 & 16.35 & 58.65 \\
imported tomatoes & 0.68 & 0.00 & 0.00 & 100.00 \\
oranges & 0.00 & 0.65 & 16.22 & 82.43 \\
\hline \hline
\end{tabular}


Table 7: Summary statistics for the relative changes in current offer prices with respect to previously observed offer prices for the different products, see also equation (22).

\begin{tabular}{lccccc}
\hline \hline & & & \multicolumn{3}{c}{ number of observations } \\
\cline { 4 - 6 } leek & mean & std & total & with $\pi=0$ & with $\pi<0$ \\
\cline { 2 - 6 } domestic tomatoes & -0.37 & 1.35 & 568 & 497 & 65 \\
imported tomatoes & 0.02 & 0.49 & 395 & 390 & 4 \\
oranges & 0.00 & 0.64 & 462 & 455 & 4 \\
\hline \hline
\end{tabular}


Table 8: Contingency table for leek: relative price changes in initial offer prices and categories. If a buyer shows up, the seller makes an initial offer price which is either accepted (transaction no bargain) or rejected. Offer only happens if the buyer rejects the initial offer and walks away. Offer and counteroffer happens if the buyer responds the initial offer with a counteroffer that is rejected by the seller. Transaction with bargaining happens if the buyer responds the initial offer with a counteroffer and both parties agree on a transaction price. The relative change $\pi$ is calculated with the current offer price and the previously observed offer price.

\begin{tabular}{|c|c|c|c|c|c|}
\hline \multirow[b]{3}{*}{$\pi<0$} & \multirow[b]{2}{*}{ offer only } & \multirow[b]{2}{*}{ offer and counteroffer } & \multicolumn{2}{|c|}{ transaction } & \multirow[b]{2}{*}{ total } \\
\hline & & & no bargaining & bargaining & \\
\hline & 7.83 & 18.64 & 14.88 & 9.38 & 11.15 \\
\hline$\pi=0$ & 79.13 & 81.36 & 82.64 & 89.58 & 85.25 \\
\hline$\pi>0$ & 13.04 & 0.00 & 2.48 & 1.04 & 3.60 \\
\hline total & 100.00 & 100.00 & 100.00 & 100.00 & 100.00 \\
\hline
\end{tabular}

Note: Chi-square test of independence statistic with 6 degrees of freedom is 44.02, $\operatorname{Pr}=0.000$ 
Table 9: Explaining the behavior of the relative change in the initial offer price for leek with a linear regression. Explanatory variables are the number $\tau$ of succeeding intervals with no contact, the transformed bargaining power index $\tilde{I}_{t-1-\tau_{I}}$ that measures the relative deviation between transaction, initial and counteroffer in the previously observed interval with bargaining, the relative deviation $\Delta_{t-1-\tau_{\Delta}}$ of the offer from the counteroffer in the previously observed interval with counteroffer, and $d_{O O, t-1-\tau}$ indicates if the most recent meeting was an offer only.

\begin{tabular}{lrrr}
\hline \hline & Coefficient & t-statistic & p-value \\
\cline { 2 - 4 }$\tau$ & -.2418 & -3.64 & 0.000 \\
$\tilde{I}_{t-1-\tau_{I}}$ & 0.5620 & 3.42 & 0.001 \\
$\Delta_{t-1-\tau_{\Delta}}$ & -2.3689 & -1.84 & 0.067 \\
$d_{O O, t-1-\tau}$ & -0.3205 & 1.91 & 0.058 \\
constant & -0.2955 & -1.63 & 0.104 \\
Regression diagnostics & & \\
\hline$R^{2}$ & 0.0622 & $\bar{R}^{2}$ & 0.0547 \\
F-Stat. & 8.3 & p-value $(F$-Stat. $)$ & 0.0000 \\
\hline \hline
\end{tabular}

Note: 506 observations are included. 
Table 10: Summary statistics for the realizations of the bargaining power index for the different products. The bargaining index measures the relative deviation between transaction price and counteroffer with respect to the difference between initial offer price and counteroffer, see also equation (21).

\begin{tabular}{|c|c|c|c|c|c|c|}
\hline & mean & std & $\begin{array}{c}\text { lower } \\
\text { quartile }\end{array}$ & median & $\begin{array}{c}\text { upper } \\
\text { quartile }\end{array}$ & $\begin{array}{c}\text { number of } \\
\text { observations }\end{array}$ \\
\hline leek & 0.67 & 0.35 & 0.50 & 0.71 & 1.00 & 406 \\
\hline domestic tomatoes & 0.66 & 0.31 & 0.50 & 0.50 & 1.00 & 387 \\
\hline imported tomatoes & 0.67 & 0.35 & 0.50 & 0.67 & 1.00 & 460 \\
\hline oranges & 0.57 & 0.25 & 0.40 & 0.60 & 0.75 & 442 \\
\hline
\end{tabular}

Note: the transaction price is missing for 8 observations of transactions with bargaining. So, we can calculate the index only for 1695 observations. 